\title{
Differential gene expression in femoral bone from red junglefowl and domestic chicken, differing for bone phenotypic traits Carl-Johan Rubin ${ }^{1}$, Johan Lindberg ${ }^{2}$, Carolyn Fitzsimmons 3 , Peter Savolainen ${ }^{2}$, Per Jensen ${ }^{4}$, Joakim Lundeberg ${ }^{2}$, Leif Andersson ${ }^{3,5}$ and Andreas Kindmark*1
}

Address: ${ }^{1}$ Department of Medical Sciences, Uppsala University, Sweden, ${ }^{2}$ Department of Gene Technology, School of Biotechnology, Royal Institute of Technology, Stockholm, Sweden, ${ }^{3}$ Department of Animal Breeding and Genetics, Swedish University of Agricultural Sciences, Uppsala, Sweden, ${ }^{4}$ IFM Biology, Linköping University, SE-585 83, Linköping, Sweden and ${ }^{5}$ Department of Medical Biochemistry and Microbiology, Uppsala University, Box 597, SE-75124 Uppsala, Sweden

Email: Carl-Johan Rubin - carl-johan.rubin@medsci.uu.se; Johan Lindberg - Johanl@biotech.kth.se;

Carolyn Fitzsimmons - Carolyn.Fitzsimmons@adelaide.edu.au; Peter Savolainen - Savo@biotech.kth.se; Per Jensen - perje@ifm.liu.se; Joakim Lundeberg - Joakim.Lundeberg@biotech.kth.se; Leif Andersson - Leif.Andersson@imbim.uu.se;

Andreas Kindmark* - Andreas.Kindmark@medsci.uu.se

* Corresponding author

Published: 2 July 2007

BMC Genomics 2007, 8:208 doi:10.1 186/1471-2164-8-208
Received: 2 April 2007

Accepted: 2 July 2007

This article is available from: http://www.biomedcentral.com/I47I-2/64/8/208

(C) 2007 Rubin et al; licensee BioMed Central Ltd.

This is an Open Access article distributed under the terms of the Creative Commons Attribution License (http://creativecommons.org/licenses/by/2.0), which permits unrestricted use, distribution, and reproduction in any medium, provided the original work is properly cited.

\begin{abstract}
Background: Osteoporosis is frequently observed among aging hens from egg-producing strains (layers) of domestic chicken. White Leghorn (WL) has been intensively selected for egg production and it manifests striking phenotypic differences for a number of traits including several bone phenotypes in comparison with the wild ancestor of chicken, the red junglefowl (RJ). Previously, we have identified four Quantitative Trait Loci (QTL) affecting bone mineral density and bone strength in an intercross between RJ and WL. With the aim of further elucidating the genetic basis of bone traits in chicken, we have now utilized cDNA-microarray technology in order to compare global RNA-expression in femoral bone from adult RJ and WL (five of each sex and population).

Results: When contrasting microarray data for all WL-individuals to that of all RJ-individuals we observed differential expression (False discovery rate adjusted p-values $<0.015$ ) for 604 microarray probes. In corresponding male and female contrasts, differential expression was observed for 410 and 270 probes, respectively. Altogether, the three contrasts between $W L$ and RJ revealed differential expression of 779 unique transcripts, 57 of which are located to previously identified QTL-regions for bone traits. Some differentially expressed genes have previously been attributed roles in bone metabolism and these were: WNT inhibitory factor I (WIFI), WD repeat-containing protein 5 (WDR5) and Syndecan 3 (SDC3). Among differentially expressed transcripts, those encoding structural ribosomal proteins were highly enriched and all 15 had lower expression in WL.

Conclusion: We report the identification of 779 differentially expressed transcripts, several residing within QTLregions for bone traits. Among differentially expressed transcripts, those encoding structural ribosomal proteins were highly enriched and all had lower expression levels in WL. In addition, transcripts encoding four translation initiation and translation elongation factor proteins also had lower expression levels in $\mathrm{WL}$, possibly indicating perturbation of protein biosynthesis pathways between the two populations. Information derived from this study could be relevant to the bone research field and may also aid in further inference of genetic changes accompanying animal domestication.
\end{abstract}




\section{Background}

Osteoporosis is a complex multifactorial disease that constitutes a major public health problem in our steadily aging human population. The disease is characterized by an altered bone metabolism leading to reduced bone mineral density (BMD) and degeneration of bone tissue, and thus an increase in bone fragility and risk of fracture. It has been estimated that every other female, but also every fourth male will sustain an osteoporotic fracture during their lifetime [1]

Bone metabolism is complex, influenced by genetic, environmental and life style factors. Twin studies show that genetic factors play an important role in the development of different skeletal phenotypes coupled to fractures and even to the incidence of fracture itself. For example, genetic factors have been estimated to account for 70$80 \%$ of the variance in bone mineral density (BMD) $[2,3]$ and for $25-35 \%$ of the risk for fracture [4]. A multitude of genes, some of which remain to be identified are involved in bone metabolism, and normal inter-individual variation in traits such as BMD and bone strength are thus most likely dependent on the combined subtle effects of many alleles.

Chicken (Gallus gallus) has traditionally been used as a model species in various branches of biology such as embryology, immunology, behavior and reproductive research [5]. The recently released draft sequence of the chicken genome [6] has made chicken an attractive model species also for genetic studies. The size of the chicken genome is about one third of the human genome size but with approximately the same number of genes and therefore has a higher gene density, which facilitates genetic studies. Furthermore, birds possess a unique evolutionary position within the vertebrate lineage, and are therefore particularly interesting for comparative genomics.

The red junglefowl (RJ) is the wild ancestor of domestic chicken. Domestication of chicken is believed to have been initiated in South-East Asia several thousand years ago [7], although several additional events of domestication may have occurred more recently. Selection in domestic breeds for traits beneficial in meat and egg production has manifested great phenotypic differences in body composition between wild-type and domestic chicken, and between domestic breeds. The phenotypic heterogeneity present among extant chicken populations presents opportunities for the identification of genetic elements on which selection has acted.

In chicken as well as in man, cortical and trabecular bone provide the mineralized framework enabling locomotion through bones acting as levers for muscles. Bone tissue provides structural support and protection for internal organs and has various metabolic functions. In the sexually mature female bird, dietary calcium and skeletal hydroxyapatite are both utilized as sources of calcium for deposition in eggshells. Elevation in levels of estrogen shortly before the onset of egg laying stimulates formation of a bone type called medullary bone, which throughout the egg-laying period acts as a labile calcium store mobilized to form eggshells [8]. Medullary and cortical bone are both resorbed in response to egg-laying, but since medullary bone is remodeled at a much higher rate than cortical bone there is a decline in cortical bone mass during the productive period [9]. Subsequent cortical bone loss results in bone fragility due to low amounts of structural bone and at the end of lay and osteoporosis is frequently observed in hens from commercial eggproduction facilities [10]. In chicken as well as in man, osteoporosis is a disease manifested by bone fragility late in life, but the functional aspects of the disease differ between the two species. In chicken the major mechanism appears to be significant remodeling of medullary bone occurring at the expense of cortical bone remodeling during long productive periods when levels of estrogen are high. This is in contrast to the human situation, where the post-menopausal decline in estrogen is acknowledged as an important contributing factor to the development of disease. Thus, the process by which the disease develops is likely to differ between man and chicken. In man, low peak bone mass is a strong positive predictor for the development of osteoporosis and therefore it is important to identify genetic variants governing peak bone mass. The main objective of this study was to identify genes which are responsible for differences in peak bone mass in chicken; as such genes could prove important to bone metabolism also in man.

White Leghorn (WL) is a domestic breed which during the last century has been intensely selected for egg production and consequently WL and RJ exhibit large differences in bone phenotypes, with BMD differing as much as $50 \%$ between hens of the two populations at peak bone mass [11]. In a three-generation intercross between WL and wild-type red junglefowl (RJ), we have previously identified four significant and several suggestive Quantitative Trait Loci (QTL) affecting various traits of femoral bone [11].

In man and in animal models, many loci with effects on bone traits have been identified by linkage- and QTL-analyses (reviewed in [12]). However, the path from QTL to the identification of causative genes has often proven difficult. A commonly used approach in animal models is repeated backcrossing to generate congenic lines, but even with such efforts, QTL-intervals are often broad, containing multiple candidate genes. Genetic differences causative of QTLs may affect gene expression, either through 
cis-effects on transcription of adjacent genes $[13,14]$ or through trans-acting effects, whereby transcription from loci not necessarily in the chromosomal vicinity of the QTL may be affected. Therefore, global gene expression profiling in parental populations may provide crucial information on QTL effects that facilitates the identification of the causal gene.

In this study, gene expression profiling and QTL-analysis have been combined, as these together could facilitate identification of molecular pathways and ultimately genes whose perturbation has resulted in bone phenotypic variation. As the chickens studied are at the age of peak bone mass, this study is primarily aimed at identifying loci contributing to bone acquisition rather than to bone loss and osteoporosis. Information derived from the present study may provide novel insights regarding the genetic regulation of bone tissue in vertebrates and could enable discovery of alleles conferring high or low BMD and thus novel targets for pharmacological prevention of osteoporosis.

\section{Results}

\section{B-test for differential expression}

The significance threshold for differential expression (DE) was set at False Discovery Rate (FDR) adjusted p-values (q-values) $=0.015$. In Table 1 numbers and details of DE probes identified in eight separate contrasts are summarized. When all RJ-individuals were compared to all WLindividuals, DE was observed for 604 probes. DE between males of the two strains was observed for 410 probes and the corresponding female comparison revealed DE for 270 probes. A total number of 837 probes, corresponding to 779 unique transcripts were identified as DE in any of the three latter contrasts (Additional File 1) and overlap of $\mathrm{DE}$ between contrasts is presented as a Venn-diagram in Figure 1. Volcano plots in Figure 2 illustrate global distributions of $\log 2$ (fold change in expression) (M-values) and q-values for all three contrasts performed between RJ and WL. Details regarding the 85 probes for which DE was observed in all three contrasts are presented in Table 2 and hierarchical clustering of these is presented as a heat map in Figure 3. Hierarchical clustering was also performed for all 837 probes showing DE in any contrast between the two chicken strains (Additional File 2). Close to two thirds (63\%) of the probes showing DE-between females of the two strains had lower expression in WL females, which is a highly significant bias $\left(\chi_{2}\right.$, d.f. $\left.=1, \mathrm{P}<0.001\right)$. There was no apparent difference in the direction of differential expression between males where $48 \%$ of probes showed lower expression in WL.

Validation of differential expression by quantitative $P C R$ Glyceraldehyde 3-phosphate dehydrogenase (GAPDH) was used as endogenous control probe for the microarray, and had been spotted in different concentrations in many
Table I: Numbers of probes for which differential expression (qvalues $<0.015$ ) was observed in all contrasts performed.

\begin{tabular}{lccc}
\hline Comparison & $\begin{array}{c}\text { Number of } \\
\text { DE-transcripts }\end{array}$ & $\begin{array}{c}\text { More } \\
\text { expression in } \\
\text { RJ (\%) }\end{array}$ & $\begin{array}{c}\text { More } \\
\text { expression in } \\
\text { males (\%) }\end{array}$ \\
\hline WL vs. RJ & 604 & 56 & NA \\
WLM vs. RJM & 410 & 48 & NA \\
WLF vs. RJF & 270 & 63 & NA \\
WLM vs. WLF & 2769 & NA & 61 \\
RJM vs. RJF & 1492 & NA & 56 \\
WLM vs. RJF & 2164 & 45 & 55 \\
WLF vs. RJM & 3214 & 60 & 60 \\
M vs. F & 3372 & NA & 59 \\
\hline
\end{tabular}

WLM $=$ White Leghorn males, $W L F=$ White Leghorn females, $R J M=$ red junglefowl males, RJF = red junglefowl females. NA: Not applicable

separate spots. Upon examination of microarray fluorescence data one WL male was found to express GAPDH in levels around 50\% lower than the other 19 individuals (Additional File 3). Since GAPDH had been chosen as reference gene, this individual was excluded from qPCR analyses.

Nine genes were chosen for verification of DE by quantitative PCR (qPCR). These nine genes were identified as DE between WL and RJ in the microarray analysis, some of them with high statistical significance for DE while others had q-values only slightly below 0.015. Data from qPCR revealed statistically significant $\mathrm{DE}(\mathrm{P}<0.05$ in Student's t-test) between WL and RJ for all nine transcripts. Results from qPCR-analysis are presented in Figure 4 and in Figure 5. In Figure 6, M-values observed in qPCR-analysis are presented together with corresponding values from the microarray analysis.

\section{Differential expression in QTL-regions for femoral bone traits}

In total 916 probes on the microarray were present in the four QTL-regions (ecirc1 = 147 probes, $n c$-bmd1 $=354$ probes, $b m d 1=148$ probes and tors $1=267$ probes $)$. Of 837 probes showing DE between WL and RJ, 60 were localized to QTL-regions (Table 3) and these correspond to 57 unique transcripts. In Figure 7, relative expression of the 60 DE probes is graphically presented along each QTLinterval. Of 13,907 probes spotted on the microarray, $6.6 \%$ were present within QTL regions. Out of 837 probes showing DE, 7.2\% were localized to QTL-regions. Thus, there was no apparent overrepresentation of DE in QTLregions.

\section{Gene ontology pathway analysis}

GO-analyses of DE-transcripts revealed statistically significant overrepresentation of functional classes belonging to all three top-level ontologies (cellular component, molecular function and biological process). Transcripts 
Table 2: Top table of 85 microarray probes identified as differentially expressed $(q<0.015)$ in all three contrasts between White Leghorn and red junglefowl (male vs. male, female vs. female and all WL vs. all RJ)

\begin{tabular}{|c|c|c|c|c|c|}
\hline GenBank ID & Ensembl gene ID & Position & Annotation ${ }^{1}$ & $M^{2}$ & q-value ${ }^{3}$ \\
\hline [GenBank:CN2|79|3] & ENSGALG000000 I8770 & Un: $28.3 \mathrm{Mb}$ & NA & -0.40 & $3.2 \mathrm{E}-12$ \\
\hline [GenBank:CN2299II] & ENSGALG000000 I 3482 & Un: $21.4 \mathrm{Mb}$ & NA & -0.38 & $9.8 \mathrm{E}-11$ \\
\hline [GenBank:CN228750] & ENSGALG00000016807 & $\mathrm{I}: 140.6 \mathrm{Mb}$ & Lim and senescent cell-antigen like domains I (LIMSI) & -0.86 & $9.8 \mathrm{E}-11$ \\
\hline [GenBank:CN225543] & ENSGALG000000I 2809 & 2: $67.1 \mathrm{Mb}$ & Peroxisomal D3,D2-enoyl-CoA isomerase (PECl) & -0.43 & $2.7 \mathrm{E}-09$ \\
\hline [GenBank:CN22357I] & ENSGALG000000 I 4429 & Un: $60.2 \mathrm{Mb}$ & similar to trans-golgi network protein 2 (TGOLN2) & -0.56 & $5.0 \mathrm{E}-09$ \\
\hline [GenBank:CN219393] & ENSGALG00000008774 & 3: $104.9 \mathrm{Mb}$ & Paralogue to PBX/knotted I homeobox I (PKNOXI) & -0.35 & $5.5 \mathrm{E}-09$ \\
\hline [GenBank:BU4I0845] & ENSGALG00000005079 & 6: $16.5 \mathrm{Mb}$ & Vinculin (VCL) & -0.46 & $8.9 \mathrm{E}-09$ \\
\hline [GenBank:CN232734] & ENSGALG00000016171 & $2: 151.3 \mathrm{Mb}$ & protein-tyrosine kinase 2 (PTK2) & -0.34 & $1.7 \mathrm{E}-08$ \\
\hline [GenBank:CN218021] & ENSGALG000000 I 8770 & Un: $28.3 \mathrm{Mb}$ & NA & -0.41 & 2.1 E-08 \\
\hline [GenBank:CN225644] & ENSGALG00000002659 & 17: $7.9 \mathrm{Mb}$ & WD repeat domain 5 protein (WDR5) & -0.45 & $1.4 \mathrm{E}-07$ \\
\hline [GenBank:CN238026] & ENSGALG00000000978 & $21: 889 \mathrm{~kb}$ & Similar to KIAA0562 & 0.44 & $2.2 \mathrm{E}-07$ \\
\hline [GenBank:CN234176] & ENSGALG00000016171 & $2: 151.4 \mathrm{Mb}$ & protein-tyrosine kinase 2 (PTK2) & -0.39 & $2.4 \mathrm{E}-07$ \\
\hline [GenBank:CN236I44] & ENSGALG00000003797 & 7: $4.5 \mathrm{Mb}$ & NA & 0.70 & $2.6 \mathrm{E}-07$ \\
\hline [GenBank:CN236164] & ENSGALG000000I5289 & $3: 69.8 \mathrm{Mb}$ & Armadillo repeat domain containing 2 (ARMC2) & 0.56 & $2.6 \mathrm{E}-07$ \\
\hline [GenBank:CN229608] & ENSGALG00000007968 & $\mathrm{l}: 64 \mathrm{l} \mathrm{kb}$ & Putative orthologue to FAM40B & -0.25 & $2.6 \mathrm{E}-07$ \\
\hline [GenBank:CN236322] & ENSGALG00000003078 & 18: $6.0 \mathrm{Mb}$ & similar to monocyte to macrophage differentiation-associated (MMD) & -0.51 & $2.6 \mathrm{E}-07$ \\
\hline [GenBank:CN225020] & ENSGALG00000020260 & 4: $16.7 \mathrm{Mb}$ & progesterone receptor membrane component I (PGRMCI) & -0.44 & $2.7 \mathrm{E}-07$ \\
\hline [GenBank:CN235998] & ENSGALG00000006921 & I5: $9.3 \mathrm{Mb}$ & developmentally regulated GTP binding protein I (DRGI) & 0.32 & $3.8 \mathrm{E}-07$ \\
\hline [GenBank:CN224535] & ENSGALG000000I6323 & $\mathrm{I}: 121.5 \mathrm{Mb}$ & $\begin{array}{l}\text { Putative orthologue to Pyruvate dehydrogenase kinase isozyme } 3 \\
\text { (PDK3) }\end{array}$ & 0.26 & 6.I E-07 \\
\hline [GenBank:CN233472] & ENSGALG00000005079 & 6: $16.5 \mathrm{Mb}$ & Vinculin (VCL) & -0.34 & 6.1 E-07 \\
\hline [GenBank:CN222595] & ENSGALG000000048I8 & $15: 6.5 \mathrm{Mb}$ & $60 S$ ribosomal protein L6 (RPL6) & -0.45 & 6.I E-07 \\
\hline [GenBank:CN238036] & ENSGALG00000000978 & $21: 889 \mathrm{~kb}$ & Similar to KIAA0562 & 0.40 & $7.9 \mathrm{E}-07$ \\
\hline [GenBank:CN226213] & & $\mathrm{I}: 130.1 \mathrm{Mb}$ & NA & -0.40 & $2.9 \mathrm{E}-06$ \\
\hline [GenBank:CN229954] & ENSGALG0000000794I & $5: 21.2 \mathrm{Mb}$ & Similar to human $\mathrm{CI}$ lorf74 protein & 0.17 & $3.4 \mathrm{E}-06$ \\
\hline [GenBank:CN217480] & ENSGALG00000003107 & II: $2.1 \mathrm{Mb}$ & Autocrine motility factor receptor, isoform 2 (AMFR) & -0.15 & $3.4 \mathrm{E}-06$ \\
\hline$[$ GenBank:CN221901] & & NA & NA & -0.63 & 4.0 E-06 \\
\hline [GenBank:CN225340] & ENSGALG00000022549 & Un: $49.4 \mathrm{Mb}$ & $\begin{array}{l}\text { Putative orthologue to } \mathrm{V} \text {-set and transmembrane domain containing } \\
\text { (VSTMI) }\end{array}$ & -0.67 & $4.3 \mathrm{E}-06$ \\
\hline [GenBank:CN227456] & & $2: 3.8 \mathrm{Mb}$ & NA & -0.59 & $4.3 \mathrm{E}-06$ \\
\hline [GenBank:CN2|8246] & ENSGALG00000024009 & $5: 680 \mathrm{~kb}$ & NA & 0.24 & $5.5 \mathrm{E}-06$ \\
\hline [GenBank:CN23298I] & ENSGALG00000000212 & $\mathrm{Z:} 43.0 \mathrm{Mb}$ & $\begin{array}{l}\text { Growth arrest and DNA-damage-inducible protein GADD45 beta } \\
\text { (GADD45B) }\end{array}$ & -0.28 & $5.5 \mathrm{E}-06$ \\
\hline [GenBank:CN237898] & & 26: $4.8 \mathrm{Mb}$ & NA & -0.25 & $5.5 \mathrm{E}-06$ \\
\hline [GenBank:CN230682] & & Un: $33.1 \mathrm{Mb}$ & NA & 0.37 & $6.0 \mathrm{E}-06$ \\
\hline [GenBank:CN23047I] & ENSGALG000000I5972 & $\mathrm{I}: 108.8 \mathrm{Mb}$ & interferon gamma receptor 2 (IFNGR2) & -0.36 & $6.0 \mathrm{E}-06$ \\
\hline [GenBank:CN223293] & & NA & NA & 0.34 & $6.2 \mathrm{E}-06$ \\
\hline [GenBank:BU303036] & ENSGALG000000I3094 & 2: $83.0 \mathrm{Mb}$ & Dopa decarboxylase (DDC) & -0.34 & $1.3 \mathrm{E}-05$ \\
\hline [GenBank:CN218709] & ENSGALG0000000I564 & 19: $3.3 \mathrm{Mb}$ & Sarcoplasmic/endoplasmic reticulum calcium ATPase 3 (SERCA3) & -0.33 & I.3 E-05 \\
\hline [GenBank:CN226292] & & $4: 51.2 \mathrm{Mb}$ & NA & -0.46 & $1.6 \mathrm{E}-05$ \\
\hline [GenBank:CN226240] & ENSGALG00000022145 & Un: $45.0 \mathrm{Mb}$ & Cell division cycle associated 8 (CDCA8) & -0.67 & $1.6 \mathrm{E}-05$ \\
\hline [GenBank:CN237835] & ENSGALG0000000I573 & 19: $3.3 \mathrm{Mb}$ & $\begin{array}{l}\text { Putative orthologue to purinergic receptor P2X ligand-gated ion channel } \\
\text { I (P2RXI) }\end{array}$ & -0.30 & $2.0 \mathrm{E}-05$ \\
\hline [GenBank:CN218191] & ENSGALG000000I5960 & 4: $89.4 \mathrm{Mb}$ & Putative orthologue to Ribose-5-phosphate isomerase (RPIA) & -0.22 & $2.5 \mathrm{E}-05$ \\
\hline [GenBank:CN218073] & ENSGALG00000008285 & $\mathrm{I}: 13.9 \mathrm{Mb}$ & NA & -0.33 & $2.5 \mathrm{E}-05$ \\
\hline [GenBank:CN225607] & & 3: $134.8 \mathrm{Mb}$ & NA & 0.29 & $2.7 \mathrm{E}-05$ \\
\hline [GenBank:CN224I44] & ENSGALG0000000I024 & $21: 960 \mathrm{~kb}$ & Putative orthologue to Protein FAM79A & 0.22 & 3.1 E-05 \\
\hline [GenBank:CN234653] & ENSGALG000000044I4 & $5: 1.15 \mathrm{Mb}$ & Putative orthologue to leucine zipper protein 2 (LUZP2) & -0.79 & 3.1 E-05 \\
\hline [GenBank:CN232675] & ENSGALG00000002384 & $7: 289 \mathrm{~kb}$ & NA & 0.19 & 3.6 E-05 \\
\hline [GenBank:CN229033] & & I: $6.3 \mathrm{Mb}$ & NA & -0.35 & 3.6 E-05 \\
\hline [GenBank:CN220674] & ENSGALG000000I5842 & $\mathrm{I}: 107.9 \mathrm{Mb}$ & $\begin{array}{l}\text { Putative orthologue to T-cell lymphoma invasion and metastasis I } \\
\text { (TIAMI) }\end{array}$ & -0.22 & 3.6 E-05 \\
\hline [GenBank:CN225767] & ENSGALG00000008686 & $2: 19.8 \mathrm{Mb}$ & Putative orthologue to tRNA (cytosine-5-)-methyltransferase (TRDMTI) & 0.26 & $3.8 \mathrm{E}-05$ \\
\hline [GenBank:CN228075] & ENSGALG000000 I 4880 & $\mathrm{Z}: 14.2 \mathrm{Mb}$ & Putative orthologue to Poly ADP-ribose polymerase 8 (PARP8) & -0.40 & $3.9 \mathrm{E}-05$ \\
\hline [GenBank:CN236904] & ENSGALG00000004823 & 8: $8.4 \mathrm{Mb}$ & Ring finger protein 2 (RNF2) & 0.19 & 4.4 E-05 \\
\hline [GenBank:CN22772I] & ENSGALG00000024253 & Un: $21.8 \mathrm{Mb}$ & $N A^{\circ}$ & 0.29 & 4.6 E-05 \\
\hline [GenBank:CN219383] & & Un: $57.4 \mathrm{Mb}$ & NA & -0.21 & 4.8 E-05 \\
\hline$[$ GenBank:CN218286] & & $\mathrm{I}: 16.9 \mathrm{Mb}$ & NA & 0.35 & $5.9 \mathrm{E}-05$ \\
\hline [GenBank:BU383276] & & 7: $5.02 \mathrm{Mb}$ & NA & -0.45 & $6.2 \mathrm{E}-05$ \\
\hline [GenBank:CN228342] & ENSGALG0000000498I & 12: $5.12 \mathrm{Mb}$ & tRNA-splicing endonuclease subunit Sen2 (TSEN2) & -0.20 & $6.5 \mathrm{E}-05$ \\
\hline [GenBank:CN219649] & & I8: $9.2 \mathrm{Mb}$ & NA & -0.39 & $6.5 \mathrm{E}-05$ \\
\hline [GenBank:CN235/29] & ENSGALG000000I5976 & $\mathrm{I}: 108.8 \mathrm{Mb}$ & Putative orthologue to Transmembrane protein 50B (TMEM50B) & -0.36 & $6.9 \mathrm{E}-05$ \\
\hline [GenBank:CN222892] & ENSGALG000000 I I 834 & 4: $55.1 \mathrm{Mb}$ & Nucleoside diphosphate-linked moiety $X$ motif 6 (NUDT6) & 0.27 & $6.9 \mathrm{E}-05$ \\
\hline [GenBank:CN227/90] & ENSGALG000000I5637 & $2: 122.5 \mathrm{Mb}$ & Putative orthologue to 60 S ribosomal protein L7 (RPL7) & -0.43 & $8.8 \mathrm{E}-05$ \\
\hline
\end{tabular}


Table 2: Top table of 85 microarray probes identified as differentially expressed $(q<0.015)$ in all three contrasts between White Leghorn and red junglefowl (male vs. male, female vs. female and all WL vs. all RJ) (Continued)

\begin{tabular}{|c|c|c|c|c|c|}
\hline [GenBank:CN235632] & ENSGALG000000|40II & $\mathrm{I}: 69.3 \mathrm{Mb}$ & Putative orthologue to lymphoid-restricted membrane protein (LRMP) & -0.35 & $9.3 \mathrm{E}-05$ \\
\hline [GenBank:CN232385] & ENSGALG00000009822 & 3: $23.0 \mathrm{Mb}$ & NA & 0.18 & $9.9 \mathrm{E}-05$ \\
\hline [GenBank:CN217382] & ENSGALG00000005587 & 5: $9.7 \mathrm{Mb}$ & Eukaryotic translation initiation factor 4 gamma 2 (EIF4G2) & -0.29 & I.2 E-04 \\
\hline [GenBank:CN222062] & & $\mathrm{II}: 8.3 \mathrm{Mb}$ & NA & 0.26 & I.4 E-04 \\
\hline [GenBank:CN218760] & ENSGALG000000 I 1031 & 8: $29.0 \mathrm{Mb}$ & Janus kinase I (JAKI) & -0.32 & $1.8 \mathrm{E}-04$ \\
\hline [GenBank:CN230192] & & $*$ & gi| $212798 \mid \pm$ & 0.97 & 2.I E-04 \\
\hline [GenBank:CN227388] & & $*$ & gi| $28971912 \mid \pm$ & 1.24 & $2.5 \mathrm{E}-04$ \\
\hline [GenBank:CN234584] & & $*$ & gi| II8084693| \pm & 1.22 & $2.5 \mathrm{E}-04$ \\
\hline [GenBank:CN222174] & ENSGALG00000007378 & $\mathrm{I}: 79.9 \mathrm{Mb}$ & NA & 0.20 & $2.9 \mathrm{E}-04$ \\
\hline [GenBank:CN219692] & & 23: $1.4 \mathrm{Mb}$ & NA & 0.24 & $3.0 \mathrm{E}-04$ \\
\hline [GenBank:CN217559] & ENSGALG0000000962I & Un: $20.4 \mathrm{Mb}$ & Putative orthologue to gamma actin (ACTG) & -0.53 & $3.5 \mathrm{E}-04$ \\
\hline [GenBank:CN222240] & ENSGALG000000I4494 & Un: $42.5 \mathrm{Mb}$ & Putative orthologue to vacuolar protein sorting I6 (VPSI6) & 0.17 & $3.8 \mathrm{E}-04$ \\
\hline [GenBank:CN23577I] & ENSGALG00000008285 & $\mathrm{I}: 13.9 \mathrm{Mb}$ & $\begin{array}{l}\text { Putative orthologue to N-acyl-phosphatidylethanolamine- } \\
\text { hydrolyzingphospholipase D (NP_94534I.2) }\end{array}$ & -0.28 & $3.8 \mathrm{E}-04$ \\
\hline [GenBank:CN227888] & ENSGALG00000006545 & Un: $33.2 \mathrm{Mb}$ & Ran-binding protein 2 (RanBP2) & -0.42 & $3.8 \mathrm{E}-04$ \\
\hline [GenBank:DQ21 1077] & ENSGALG00000024372 * & 16: $40 \mathrm{~kb} *$ & MHC class I antigen (Fragment) & -0.70 & 4.4 E-04 \\
\hline [GenBank:CN228106] & ENSGALG00000022764 & & NA & 0.13 & $4.6 \mathrm{E}-04$ \\
\hline [GenBank:CN217063] & ENSGALG0000000920I & I4: I5.0 Mb & Putative orthologue to Cyclin F (CCNF) & -0.29 & $5.7 \mathrm{E}-04$ \\
\hline [GenBank:CN234096] & ENSGALG000000I4339 & Un: II.3 Mb & $\begin{array}{l}\text { Putative orthologue to Biogenesis of lysosome-related organelles } \\
\text { complex-I subunit } 3 \text { (BLOCIS3) }\end{array}$ & -0.42 & $6.0 \mathrm{E}-04$ \\
\hline [GenBank:CN220094] & ENSGALG000000 I 624I & $\mathrm{I}: \mathrm{II} .9 \mathrm{Mb}$ & $\begin{array}{l}\text { Putative orthologue to ATPase, } \mathrm{H}+\text { transporting, lysosomal, accessory } \\
\text { protein } 2 \text { (ATP6AP2) }\end{array}$ & 0.37 & $9.4 \mathrm{E}-04$ \\
\hline [GenBank:CN219753] & & $20: 5.5 \mathrm{Mb}$ & NA & 0.25 & $9.9 \mathrm{E}-04$ \\
\hline [GenBank:CN23|4|4] & ENSGALG000000 16813 & $\mathrm{I}: 14 \mathrm{I} . \mathrm{I} \mathrm{Mb}$ & NA & 0.51 & 0.0011 \\
\hline [GenBank:CN233509] & & $\mathrm{I}: 172.6 \mathrm{Mb}$ & NA & -0.22 & 0.0019 \\
\hline [GenBank:CN218972] & ENSGALG00000007I 78 & 5: $18.0 \mathrm{Mb}$ & Putative orthologue of fatty acid desaturase 2 (FADS2) & -0.32 & 0.0034 \\
\hline [GenBank:CN231098] & ENSGALG000000 I 5122 & 2: $107.4 \mathrm{Mb}$ & $\begin{array}{l}\text { Putative orthologue of TAF4b RNA polymerase II, TATAbox binding } \\
\text { protein (TBP)-associated factor, } 105 \mathrm{kDa} \text { (TAF4B) }\end{array}$ & 0.56 & 0.0046 \\
\hline [GenBank:CN222925] & ENSGALG000000 I I I 64 & 2: $33.7 \mathrm{Mb}$ & NA & -0.46 & 0.012 \\
\hline [GenBank:CN218459] & ENSGALG000000I6340 & $\mathrm{I}: 121.7 \mathrm{Mb}$ & $\begin{array}{l}\text { Putative orthologue of Eukaryotic translation initiationfactor } 2 \text { subunit } 3 \\
\text { (EIF2S3) }\end{array}$ & -0.20 & 0.014 \\
\hline
\end{tabular}

I Annotation: Gene name if available. Putative orthologues to ensemble chicken transcripts are presented when no gene name is available. NA = No annotation and is presented in cases where neither is applicable.

2 M-value: Log2(Fold difference in expression) in contrast all WL versus all RJ. Positive M-values indicate more expression in White Leghorn. 3 q-value: FDR-adjusted p-value from sex independent contrast between WL and RJ. * BLAST search of probe sequence against the chicken genome produced multiple hits \pm Represents endogenous retroviral elements. Highest scoring BLAST hit is presented.

encoding ribosomal proteins were highly enriched in the ontology "Cellular Component" and in the ontology "Molecular Function", protein biosynthesis was similarly overrepresented. Table 4 lists GO-terms overrepresented among transcripts identified as DE between RJ and WL. GO-categories overrepresented among transcripts identified as DE between males and females is presented in Additional File 7.

\section{Phenotyping of the distal femoral metaphysis by pQCT}

Mean noncortical BMD (BMD of trabecular and medullary bone) was $282 \pm 49 \mathrm{mg} / \mathrm{cm}^{3}$ for RJ females and $348 \pm$ $27 \mathrm{mg} / \mathrm{cm}^{3}$ for WL females (Additional File 4). Male pQCT images are presented in Additional File 5.

\section{Discussion}

To our knowledge, very few studies have compared global gene expression between domestic animals and their wild ancestors [15]. Numerous studies have however examined differences in global gene expression between humans and other primates [16-22] as well as between selection lines of various species [23-28]. In the field of reverse genetics, gene expression profiling has been extensively utilized for functional inference of individual genes. In the bone research field, gene expression microarrays have been restricted mainly to studies of genetically altered mice, pharmacological studies in vivo and in vitro and transfection experiments in cell-lines.

Comparative genomic and transcriptomic studies of domestic animal species can provide insights into molecular pathways which have been perturbed through selection and can ultimately lead to the identification of genes or even mutations having been selected for during the establishment of desired phenotypes in domestic lines [29]. Having chosen the path of comparative transcriptomics, experimental design is a crucial parameter, as environmental factors may otherwise be responsible for observed differences in gene expression. Comparing gene expression of wild animals captured in their natural habitat to their domestic counterparts will result in an unknown extent of differential expression due to differing environmental factors. In the present study, all chickens were hatched, housed and sacrificed in the same facility and were thus exposed to the same environment (including feed, temperature, light schedule, pathogens, etc.) throughout life. All individuals were sacrificed at 40 weeks of age which corresponds to the age of peak bone mass 


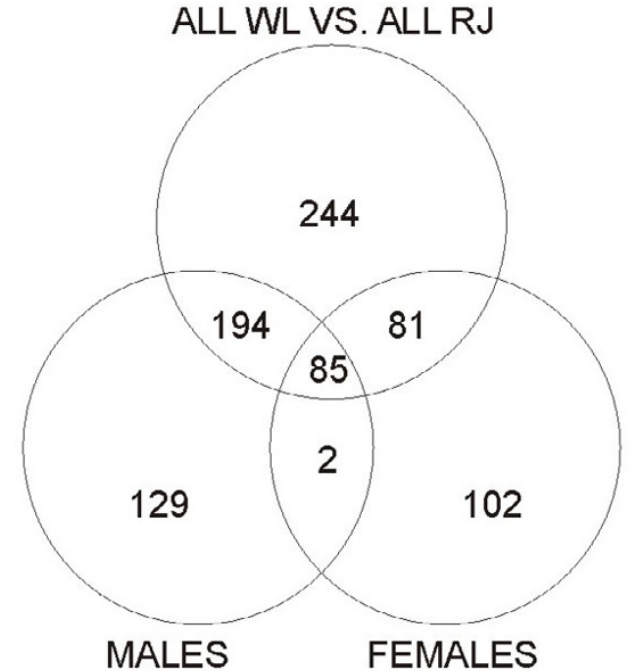

\section{Figure I}

Venn diagram indicating numbers of probes sharing differential expression (q-values $<0.015$ ) in sex specific contrasts between WL and RJ and in contrast between all WL and all RJ). Numbers within shared fields of circles indicate the number of probes exhibiting DE in overlapping contrasts.

[30]. At peak bone mass WL have mechanically stronger and denser bones than RJ, while later in their lives a large proportion of WL-hens develop osteoporosis due to their extremely high egg production. It should be noted that the two chicken lines differ in the age at which they enter sexual maturity (approximately 20 weeks of age for WL and 25 weeks of age for RJ) [31]. The difference between strains with regard to time since sexual maturity could be a confounding factor, as e.g. hormonal profiles may differ between the strains. Nevertheless, at 40 weeks of age chickens should be sexually mature, although age related decline in bone mass should not yet have been initialized.

When comparing gene expression in bone from two populations as divergent as RJ and WL, some confounding factors are difficult to eliminate. Although specific care was taken to eliminate confounding environmental factors when breeding the chickens, several remain and should be acknowledged. Such factors include differing ages at which the two chicken lines enter sexual maturity, potential relative differences in cell type abundance between lines as well as not having documented female egg-laying parameters before tissue sampling. Furthermore, the large difference in body size as well as bone size between adult $\mathrm{RJ}$ and WL constitute a potential limitation as it could lead to relative differences in cell type abundance and also differences in load applied to bones. Comparing female femurs is particularly liable to confounding factors intro-
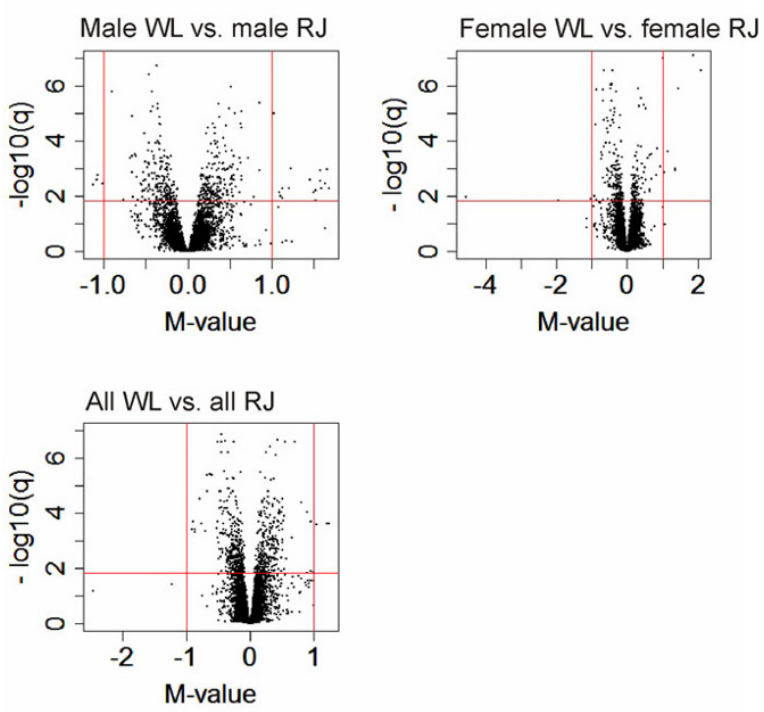

Figure 2

Volcano plots illustrating distributions of $M$ - and - $\log$ (FDRadjusted $p$-values) for all probes on microarray in three contrasts between WL and RJ. Horizontal red lines indicate DE significance threshold $(q=0.015)$ and vertical red lines indicate $M$-values of $I$ and $-I$. Positive $M$-values indicate higher expression in WL.

duced by phenotypic differences, as amounts of medullary bone can be heterogeneous. It would be optimal to compare gene expression between the two populations also at other ages, as this could help separate genes whose expression is affected factors such as load and relative differences in cell type abundance from those whose differential expression is caused by certain alleles having been fixed during domestication or evolution. Another potential bias lies in the probe composition of the microarray. The majority of the 13907 probes spotted on the microarray were derived from RJ and WL brain- and testis Expressed Sequence Tag (EST) libraries $(\mathrm{n}=12742)$, but an additional 1136 clones were specifically chosen because of their biological functions. It is possible that some genes important to bone metabolism, in particular ones with expression limited to certain cell types or those expressed in low levels, may not be represented on the microarray. Despite this potential bias in probe composition, the microarray covers a large fraction of chicken transcripts and should enable global expression profiling. It may however be worthwhile to replicate these studies utilizing commercially available oligonucleotide microarrays, which would enable expression profiling of a more complete set of chicken genes. In this study five biological replicates from each sex and strain were used, rendering a total of twenty samples. It is conceivable that analysis of a larger sample size would have enabled the detection of 


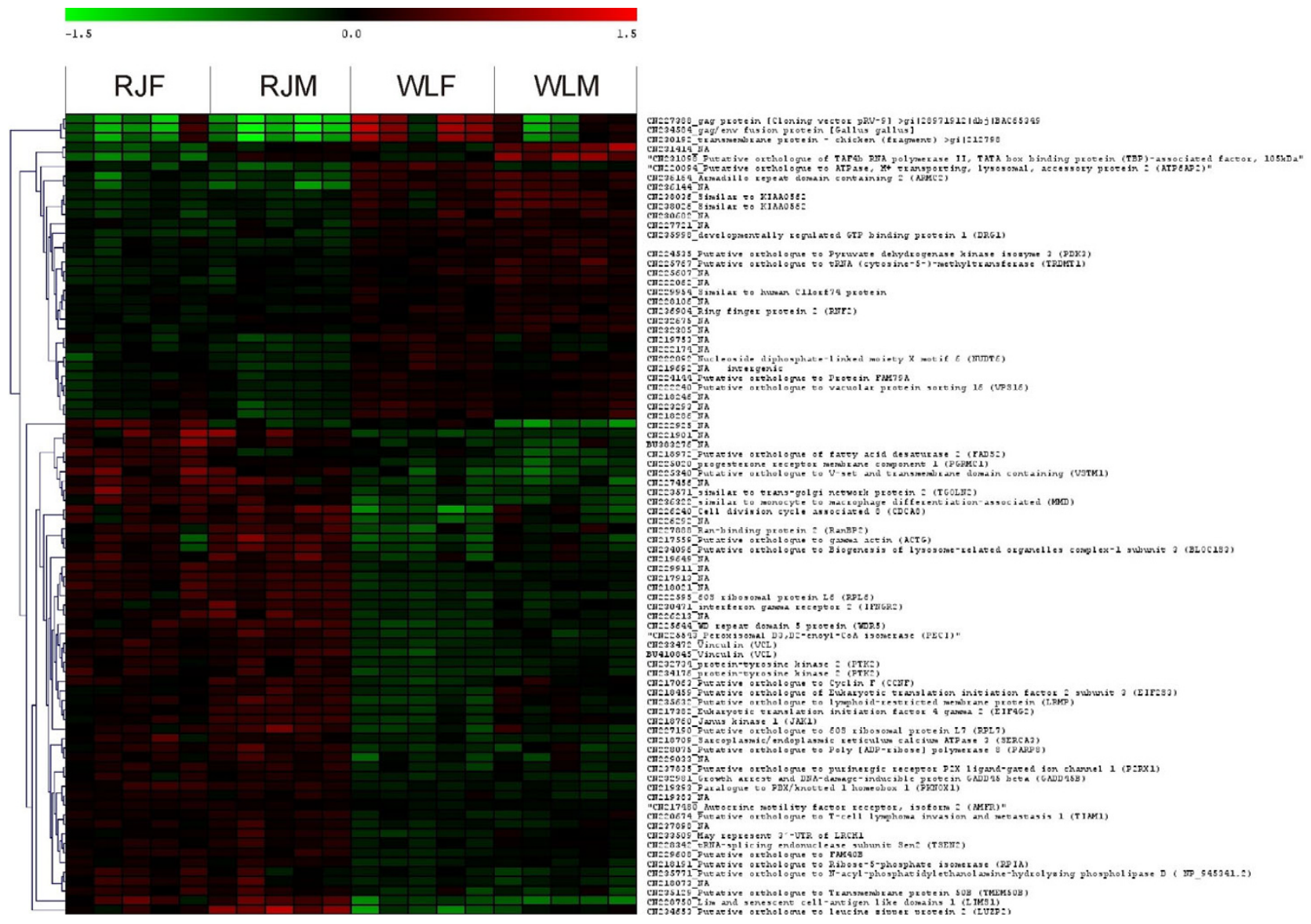

Figure 3

Hierarchical clustering of microarray data for 85 microarray probes showing differential expression in all three contrasts performed between red junglefowl and White Leghorn. Individuals (five of each sex and line) are scattered along the $x$-axis and probes are distributed along the $y$-axis. For each individual and probe, colors represent log2(sample fluorescence/reference fluorescence) according so upper scale bar (red indicates more expression in sample channel whereas green indicate more expression in reference channel). Hierarchical clustering was performed using the Euclidean metric.

additional genes as differentially expressed between RJ and WL. Furthermore, in order to infer with certainty gene expression signatures associated to differences in complex phenotypes such as $\mathrm{BMD}$, significantly larger sample sizes than those used herein accompanied by thorough phenotype data would be required.

\section{Differential expression between males and females}

Comparisons between males and females rendered the highest numbers of differentially expressed transcripts (Table 1). As expected, all females and no males expressed the female specific W-chromosome gene WPKCI, a gene believed to be involved in female sex determination in birds [32]. In male birds, the femoral midshaft consists of an inner blood filled marrow cavity surrounded by an outer lining of cortical bone. The marrow cavity of the sexually mature female bird is, in addition to blood and air, also occupied by varying amounts of medullary bone lining the endosteal surfaces of cortical bone. Consequently, the female femur contains a tissue which is absent from the male femur and it can therefore be expected that a large proportion of DE observed between sexes is dependent on relative differences in cell type abundance. Another fraction of DE transcripts is likely to be directly or indirectly caused by factors not attributed to phenotypic differences, but rather to karyotype as it was recently shown that dosage compensation of the avian $\mathrm{Z}$ is not as effective as mammalian dosage compensation [33] (in birds males have two Z-chromosomes, whereas females have one Zand one $\mathrm{W}$-chromosome). GO-categories identified as overrepresented among transcripts which exhibit DE between sexes (Additional File 7) could consequently harbor functional categories associated to cell types present in varying ratios in female and male bones. Males and females had statistically significant differences in expres- 

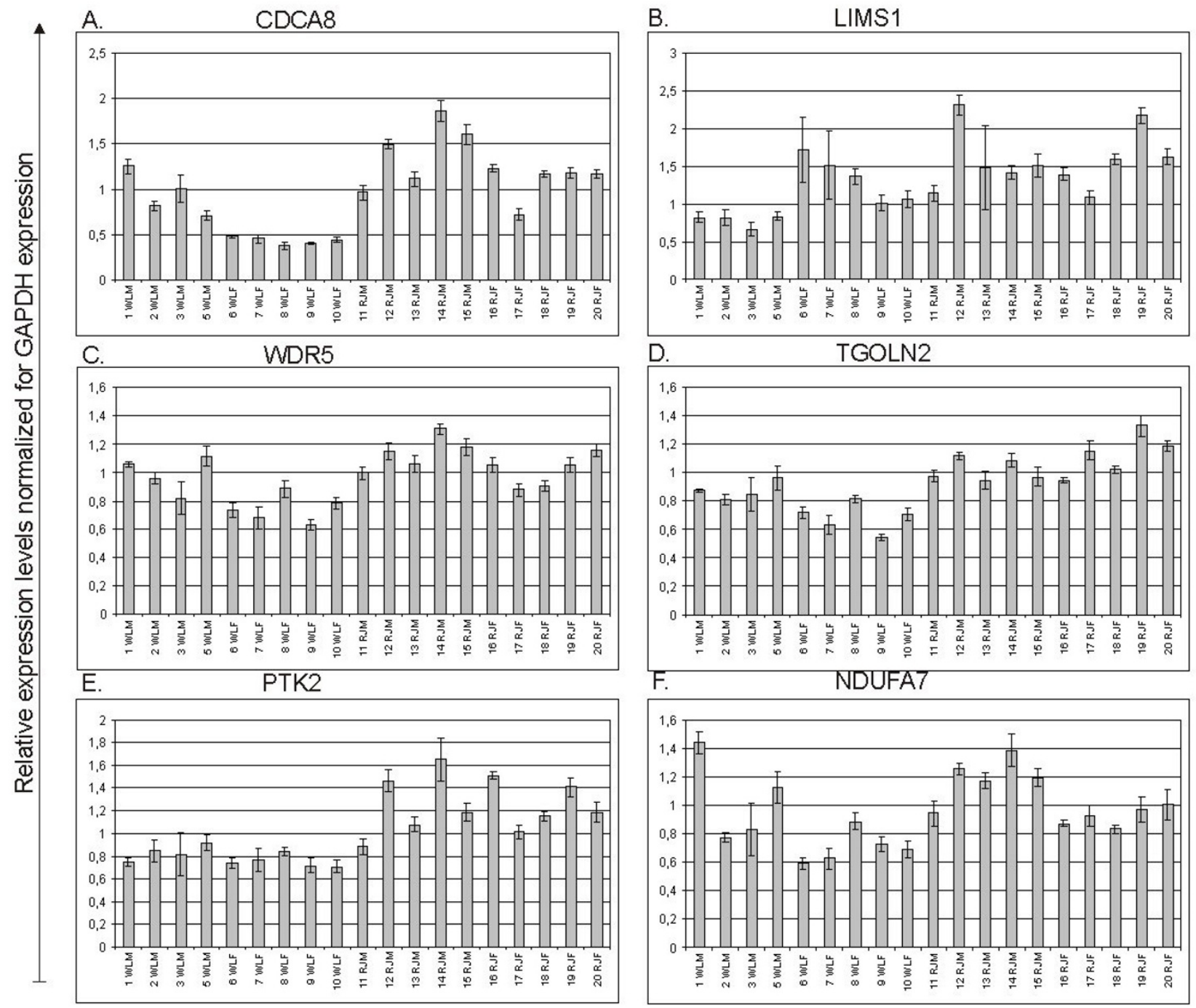

Figure 4

Results derived from quantitative PCR analysis of six transcripts expressed higher levels in the red junglefowl in the microarray analysis. Chicken individuals are presented along the $x$-axis: WLM $=$ White Leghorn male, WLF $=$ White Leghorn female, RJM $=$ red junglefowl male, $\mathrm{RJF}=$ red junglefowl female. For each transcript, expression relative to GAPDH-expression is presented on the $y$-axis. Error bars indicate standard deviations.

sion of certain known bone cell type markers. Alkaline Phosphatase $(A L P)$ was expressed in higher levels in the female $(\mathrm{M}$-value $=0.63)$ (indicating higher numbers of osteoblasts in the female bone). Phosphate-regulating Endopeptidase Homolog, X-linked (PHEX) also had higher expression in female bone $(\mathrm{M}$-value $=0.64)$, which similarly would indicate higher osteoblastic numbers in female bone. The osteoclast marker Creatine Kinase B $(C K B)$ was expressed in more than four times higher levels in female femurs than in male femurs. The higher expres- sion of markers for both osteoblasts and osteoclasts suggests that bone remodeling is accelerated in female bone, and is likely attributed to females having higher turnover rates of bone tissue.

\section{Differential expression between $R J$ and WL}

For nine selected transcripts, DE observed in the microarray analysis was verified by qPCR-analysis (Figure 6), indicating true differential expression for most probes having been identified as DE. As could be expected, the 


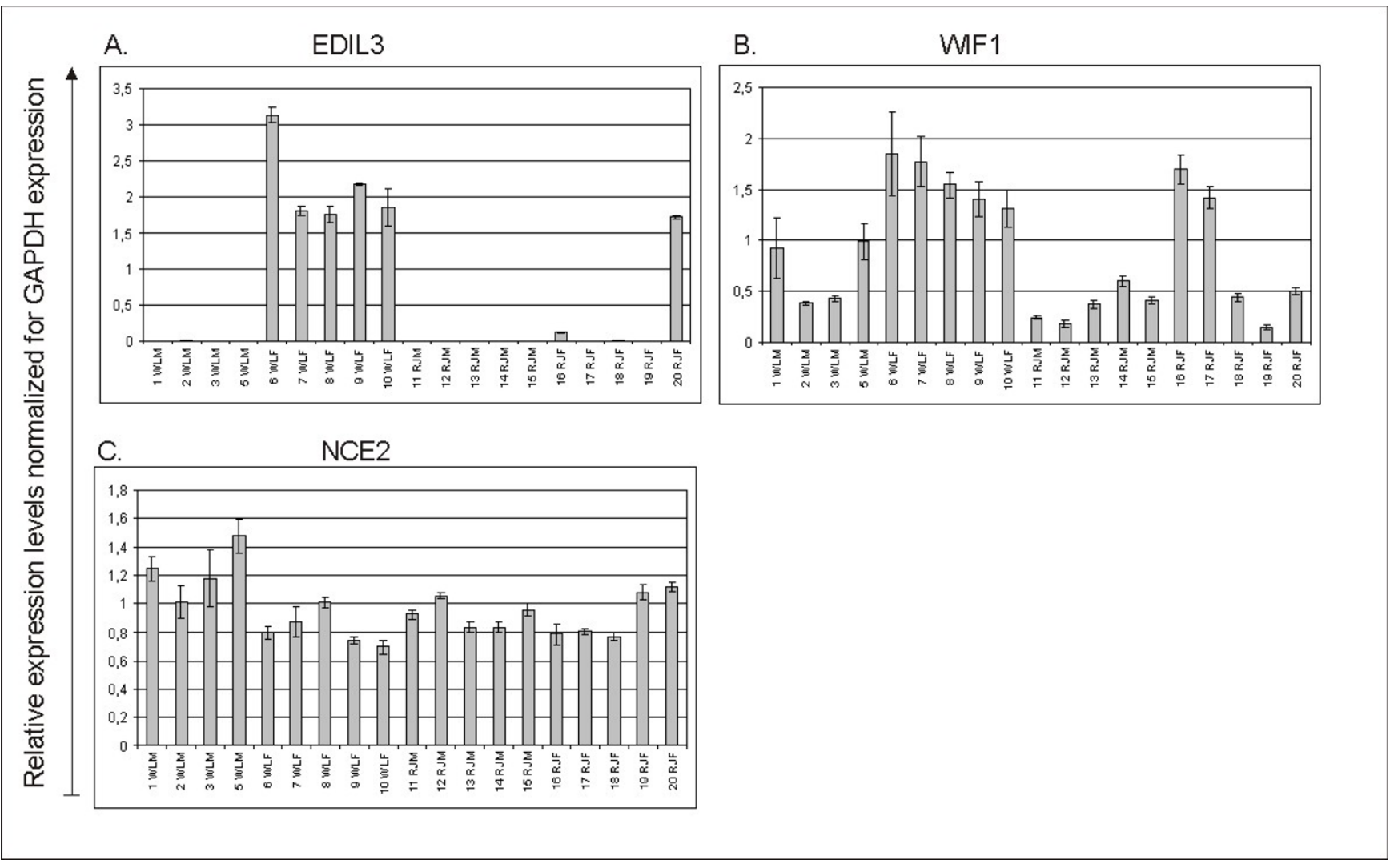

Figure 5

Results derived from quantitative PCR analysis of three transcripts expressed higher levels in the White Leghorn in the microarray analysis. Chicken individuals are presented along the $x$-axis: WLM $=$ White Leghorn male, WLF $=$ White Leghorn female, $\mathrm{RJM}=$ red junglefowl male, RJF = red junglefowl female. For each transcript, expression relative to GAPDH-expression is presented on the $y$-axis. Error bars indicate standard deviations.

magnitude of DE varied between the two methods, of which qPCR is likely to be more accurate due to having greater specificity than hybridization techniques.

Higher numbers of microarray probes showing DE were observed in contrast between males of the two strains ( $\mathrm{n}$ $=410)$ than in the corresponding female contrast ( $\mathrm{n}=$ 270 ). In reproductive female chicken the cyclical process of egg-laying is accompanied by a phase of intense bone remodeling. It is possible that the females were in different phases of bone remodeling at the time of tissue sampling and/or that female femurs had differing relative amounts of cortical or medullary bone, which could also be calcified to different degrees. Differences in bone remodeling due to egg-laying and differences caused by heterogeneous bone phenotypes could both result in female biological replicates being more heterogeneous than male ones, and could explain why less DE was seen in the female contrast. In Figure 1, it can be seen that the fraction of DE transcripts which overlap between the male specific- and the sex independent contrasts is higher than the corresponding overlapping fraction observed between the female- and sex-independent contrasts. We suggest that this can be attributed to a larger phenotypic heterogeneity among female than male biological replicates.

Phenotyping of the femurs revealed that WL females generally had slightly higher density of noncortical BMD (in the female metaphysis medullary- and bone trabecular together constitute what here is referred to as noncortical bone) in the metaphysis with mean values of $348 \pm 27$ $\mathrm{mg} / \mathrm{cm}^{3}$ for WL females and $282 \pm 49 \mathrm{mg} / \mathrm{cm}^{3}$ for RJ females (Additional File 4). From phenotyping performed by $\mathrm{pQCT}$ in an independent sample of female chicken we have observed that noncortical BMD of the femoral metaphysis is strongly positively correlated with medullary BMD of the femoral midshaft $(r=0.73)$ (Additional File $6)$. The strain differences in noncortical BMD of the metaphysis are not large enough to conclude that they can be attributed also to the femoral midshaft. Interestingly, the metaphysis of RJ female individual 19 (RJF19) had very little, if any medullary bone (Additional File 4) and con- 


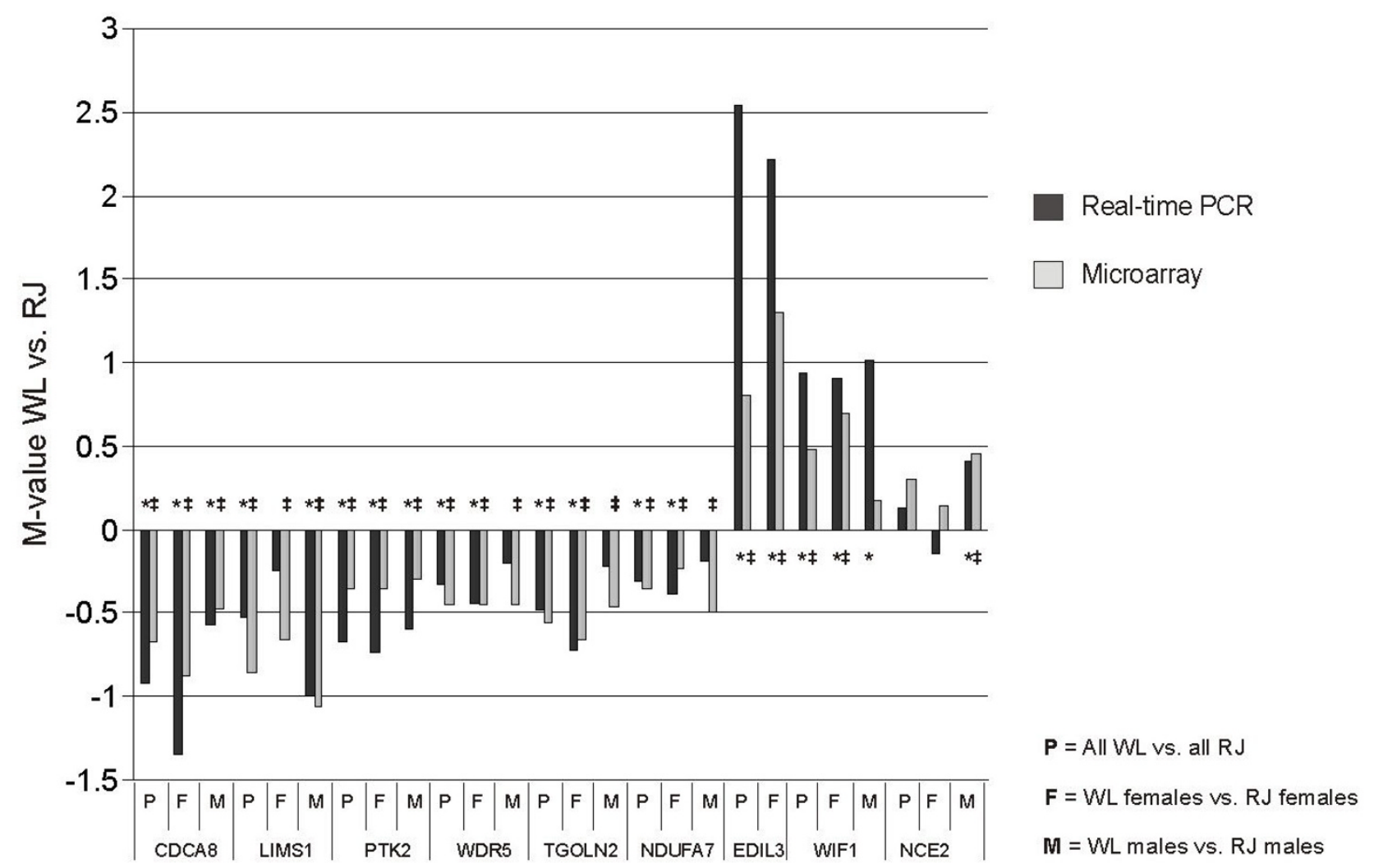

\section{Figure 6}

Comparison of results obtained by microarray-analysis and by qPCR-analysis. On y-axis, positive M-values indicate more expression in WL, whereas negative $M$-values indicate more expression in RJ. Nine genes included in qPCR-analysis are presented along $x$-axis. To indicate statistical significance in real-time PCR at the $p<0.05$ level the $*$ symbol is used. To indicate $q-$ values $<0.015$ in the microarray analysis the $\ddagger$ symbol is used.

sequently a low noncortical BMD. The absence of medullary bone from RJF19 is likely to confer absence of this bone type also in the midshaft. Exclusion of RJF19 from the female RJ vs. WL contrast did not significantly alter the set of probes for which DE was observed, nor did the exclusion result in any dramatic changes in the statistical significance of observed DE (data not presented). The femoral phenotyping was performed in the metaphysis whereas the RNA was prepared from the midshaft and the data should thus be regarded as a qualitative rather than quantitative addition to the study. pQCT-data obtained for the female femurs indicate large differences in bone size between the RJ and WL populations, but also indicate that female biological replicates should be relatively homogenous with the exception of RJF19. From the phenotyping of male femurs (Additional File 5), we draw no conclusion other than that there is an apparent size difference between the two populations.
No commonly used bone cell markers were identified as differentially expressed between RJ and WL in the sexindependent contrast, nor in the two sex-specific contrasts. However, some genes for which differential expression was observed have previously been attributed roles in bone metabolism. For example WD-repeat containing protein 5 (WDR5), which accelerates osteoblast and chondrocyte differentiation $[34,35]$ and whose expression is induced by bone morphogenic protein 2 (BMP2). Figure $4 \mathrm{C}$ and Figure 6 show that WL-individuals expressed WDR5 in lower amounts than did RJ-individuals. Over the last few years, the wnt-signaling system has been attributed roles important to bone metabolism (reviewed in [36]), and has become one of the most extensively studied signaling systems in the bone field. Wnt inhibitory factor 1 (WIF1) was identified as DE between females of the two strains, with WL having higher levels than RJ. WIF1 is a secreted protein that inhibits some wnt-proteins from 
Table 3: Differentially expressed transcripts located to QTL-regions for bone traits

\begin{tabular}{|c|c|c|c|c|c|c|}
\hline Genbank ID & Pos. ${ }^{\prime}$ & Ensembl gene ${ }^{2}$ & Annotation ${ }^{3}$ & $\mathrm{QTL}^{4}$ & $\mathrm{DE}^{5}$ & M-values 6 \\
\hline [GenBank:CN234847] & $\mathrm{I}: 30.2$ & ENSGALG00000009494 & $\begin{array}{l}\text { Putative orthologue to human THAP domain containing } 5 \\
\text { (THAP5) }\end{array}$ & ecircl & $M$ & $\begin{array}{l}0.36 \\
-0.02 \\
0.18\end{array}$ \\
\hline [GenBank:CN232736] & $1: 31.3$ & ENSGALG00000009547 & Putative orthologue to human periphilin I (PPHLNI) & ecircl & F P & $\begin{array}{l}-0.09 \\
-0.29 \\
-0.19\end{array}$ \\
\hline [GenBank:CN220162] & $\mathrm{I}: 32.4$ & & NA & ecircl & $\mathrm{P}$ & $\begin{array}{l}-0.17 \\
-0.19 \\
-0.18\end{array}$ \\
\hline [GenBank:CN223165] & $\mathrm{I}: 34.4 \pm$ & ENSGALG00000009762 & Gag polyprotein & ecircl & $M P$ & $\begin{array}{l}0.49 \\
0.32 \\
0.40\end{array}$ \\
\hline [GenBank:CN217879] & $\mathrm{I}: 35.5$ & ENSGALG00000009829 & Putative orthologue to Ribosomal protein LI8 A (RPLI8A) & ecircl & $P$ & $\begin{array}{l}-0.20 \\
-0.34 \\
-0.27\end{array}$ \\
\hline [GenBank:BUI28191] & $\mathrm{I}: 35.7$ & ENSGALG00000009867 & Wnt inhibitory factor I (WIFI) * & ecircl & $\mathrm{F}$ & $\begin{array}{l}0.17 \\
0.68 \\
0.43\end{array}$ \\
\hline [GenBank:BUII8286] & $\mathrm{I}: 35.7$ & ENSGALG00000009867 & Wnt inhibitory factor I (WIFI) * & ecircl & $\mathrm{F}$ & $\begin{array}{l}0.15 \\
0.64 \\
0.39\end{array}$ \\
\hline [GenBank:CN22409I] & $\mathrm{I}: 43.5$ & ENSGALG00000010992 & $\begin{array}{l}\text { Putative orthologue to Solute carrier family } 6 \text {, member } 15 \\
\text { (SLC6AI5) }\end{array}$ & nc-bmd I & $P$ & $\begin{array}{l}0.26 \\
0.14 \\
0.20\end{array}$ \\
\hline [GenBank:CN221299] & $\mathrm{I}: 47.0$ & & NA & nc-bmdl & MP & $\begin{array}{l}0.41 \\
0.21 \\
0.31\end{array}$ \\
\hline [GenBank:CN226131] & $\mathrm{I}: 47.2$ & ENSGALG000000 I I 325 & $\begin{array}{l}\text { NADH dehydrogenase [ubiquinone] I alpha subcomplex subunit } \\
\text { I } 2 \text { (NDUFAI2) }\end{array}$ & nc-bmd I & M & $\begin{array}{l}0.30 \\
-0.00 \\
0.14\end{array}$ \\
\hline [GenBank:CN223612] & $\mathrm{I}: 49.5$ & ENSGALG000000 I I65। & Putative orthologue to ADP-ribosylation factor-like I (ARLI) & nc-bmd l & $\mathrm{P}$ & $\begin{array}{l}0.36 \\
0.35 \\
0.36\end{array}$ \\
\hline [GenBank:CN229035] & $1: 49.9$ & ENSGALG00000023235 & NA & nc-bmd l & MP & $\begin{array}{l}-0.33 \\
-0.27 \\
-0.30\end{array}$ \\
\hline [GenBank:CN217578] & $\mathrm{I}: 50.1$ & ENSGALG000000 I I 798 & Putative orthologue to heme-binding protein I (HEBPI) & nc-bmd I & M & $\begin{array}{l}0.71 \\
0.42 \\
0.55\end{array}$ \\
\hline [GenBank:CN230393] & $\mathrm{I}: 51.0$ & ENSGALG000000 I I856 & NA & nc-bmd I & $P$ & $\begin{array}{l}0.16 \\
0.14 \\
0.15\end{array}$ \\
\hline [GenBank:CN224774] & $1: 51.0$ & ENSGALG000000II 859 & Eye-globin [UniProt:Q5QRU6] & nc-bmd I & $\mathrm{P}$ & $\begin{array}{l}-0.20 \\
-0.20 \\
-0.20\end{array}$ \\
\hline [GenBank:CN219273] & $1: 51.8$ & ENSGALG00000012013 & $\begin{array}{l}\text { Putative orthologue to Solute carrier family } 25, \text { member } 17 \\
\text { (SLC25AI7) }\end{array}$ & nc-bmd l & $\mathrm{F}$ & $\begin{array}{l}0.08 \\
0.31 \\
0.20\end{array}$ \\
\hline [GenBank:CN223291] & $1: 52.6$ & & NA & nc-bmd I & MP & $\begin{array}{l}0.48 \\
0.26 \\
0.37\end{array}$ \\
\hline [GenBank:CN221539] & $\mathrm{I}: 52.6$ & & NA & nc-bmd I & $\mathrm{P}$ & $\begin{array}{l}0.21 \\
0.30 \\
0.26\end{array}$ \\
\hline [GenBank:CN223252] & $\mathrm{I}: 52.7$ & ENSGALG00000019317 & Putative orthologue to Josephin domain-containing I (JOSDI) & nc-bmd I & MP & $\begin{array}{l}0.29 \\
0.17 \\
0.23\end{array}$ \\
\hline [GenBank:CN230599] & $\mathrm{I}: 52.8$ & & NA & nc-bmd I & $M$ & $\begin{array}{l}-0.16 \\
0.00 \\
-0.08\end{array}$ \\
\hline [GenBank:CN235584] & $1: 52.8$ & ENSGALG000000I 2247 & Putative homologue to DEAD/H BOX I7 (DDXI7) & nc-bmd I & $\mathrm{F}$ & $\begin{array}{l}0.09 \\
-0.30 \\
-0.10\end{array}$ \\
\hline [GenBank:CN23|378] & $\mathrm{I}: 52.8$ & & NA & nc-bmd I & $P$ & $\begin{array}{l}0.15 \\
0.13 \\
0.14\end{array}$ \\
\hline [GenBank:CN220256] & $1: 52.9$ & ENSGALG000000 I 2272 & NA & nc-bmd I & $P$ & $\begin{array}{l}0.38 \\
0.36 \\
0.37\end{array}$ \\
\hline [GenBank:CN221882] & $1: 53.3$ & ENSGALG000000I 2456 & $\begin{array}{l}\text { Putative orthologue to Ras-related C3 botulinum toxin substrate } 2 \\
\text { (RAC2) }\end{array}$ & nc-bmd I & M & $\begin{array}{l}-0.52 \\
-0.15 \\
-0.34\end{array}$ \\
\hline [GenBank:CN234446] & $\mathrm{I}: 55 . \mathrm{I}$ & & NA & nc-bmdl & FP & $\begin{array}{l}-0.20 \\
-0.32 \\
-0.26\end{array}$ \\
\hline
\end{tabular}


Table 3: Differentially expressed transcripts located to QTL-regions for bone traits (Continued)

\begin{tabular}{|c|c|c|c|c|c|c|}
\hline [GenBank:CN227045] & $1: 55.3$ & ENSGALG000000I2569 & Putative orthologue to F-box only protein 7 (FBXO7) & nc-bmdl & $F$ & $\begin{array}{l}-0.00 \\
-0.13 \\
-0.07\end{array}$ \\
\hline [GenBank:CN226884] & $\mathrm{I}: 55.3$ & ENSGALG000000I2619 & NA & nc-bmdI & $\mathrm{F}$ & $\begin{array}{l}-0.02 \\
-0.12 \\
-0.07\end{array}$ \\
\hline [GenBank:CN223798] & $\mathrm{I}: 56.2$ & & NA & nc-bmd l & MP & $\begin{array}{l}0.42 \\
0.27 \\
0.35\end{array}$ \\
\hline [GenBank:CN219664] & I:59.3 & & NA & nc-bmd I & MP & $\begin{array}{l}0.41 \\
0.23 \\
0.32\end{array}$ \\
\hline [GenBank:CN222216] & $\mathrm{I}: 61.2$ & & NA & nc-bmdI & M & $\begin{array}{l}0.18 \\
-0.05 \\
0.06\end{array}$ \\
\hline [GenBank:CN231349] & $\mathrm{I}: 63.0$ & & NA & nc-bmdl & $P$ & $\begin{array}{l}0.11 \\
0.13 \\
0.12\end{array}$ \\
\hline [GenBank:CN222823] & $\mathrm{I}: 63.7$ & & NA & nc-bmd I & $P$ & $\begin{array}{l}0.31 \\
0.22 \\
0.26\end{array}$ \\
\hline [GenBank:BU329405] & $\mathrm{I}: 63.9$ & ENSGALG000000I3039 & BH3-interacting domain death agonist (BID) & nc-bmdl & MP & $\begin{array}{l}-0.14 \\
-0.11 \\
-0.12\end{array}$ \\
\hline [GenBank:CN219432] & 2:57.4 & & NA & bmdl & MP & $\begin{array}{l}-0.25 \\
-0.19 \\
-0.22\end{array}$ \\
\hline [GenBank:CN233407] & $2: 63.3$ & & NA & bmdl & M & $\begin{array}{l}0.24 \\
0.02 \\
0.13\end{array}$ \\
\hline [GenBank:CN231046] & $2: 65.5$ & ENSGALG000000I 2784 & $\begin{array}{l}\text { Putative orthologue to Thioredoxin domain-containing protein } 5 \\
\text { (TXNDC5) }\end{array}$ & bmdl & M & $\begin{array}{l}0.29 \\
0.09 \\
0.19\end{array}$ \\
\hline [GenBank:BU3|8588] & $2: 66.2$ & ENSGALG000000I 2802 & $\begin{array}{l}\text { Putative orthologue to human Coagulation factor XIII A chain } \\
\text { precursor (FI3AI) }\end{array}$ & bmd I & $P$ & $\begin{array}{l}-0.44 \\
-0.46 \\
-0.46\end{array}$ \\
\hline [GenBank:CN225543] & $2: 67.0$ & ENSGALG000000I 2809 & Peroxisomal D3,D2-enoyl-CoA isomerase (PECl) & bmdl & ALL & $\begin{array}{l}-0.42 \\
-0.42 \\
-0.42\end{array}$ \\
\hline [GenBank:CN222249] & $2: 78.1$ & ENSGALG000000I 2965 & $\begin{array}{l}\text { Putative orthologue to family with sequence similarity 105, } \\
\text { member A (FAMI 05A) }\end{array}$ & bmd I & $P$ & $\begin{array}{l}-0.14 \\
-0.17 \\
-0.15\end{array}$ \\
\hline [GenBank:CN227494] & $2: 80.5$ & ENSGALG00000013041 & $\begin{array}{l}\text { Putative orthologue to T-complex protein I subunit epsilon } \\
\text { (CCT5) }\end{array}$ & bmd I & M & $\begin{array}{l}-0.27 \\
-0.06 \\
-0.16\end{array}$ \\
\hline [GenBank:BU303036] & $2: 83.0$ & ENSGALG000000। 3094 & Dopa decarboxylase (DDC) & bmdl & ALL & $\begin{array}{l}-0.26 \\
-0.40 \\
-0.33\end{array}$ \\
\hline [GenBank:CN232630] & $2: 85.8$ & & NA & bmdl & M & $\begin{array}{l}-0.21 \\
-0.01 \\
-0.11\end{array}$ \\
\hline [GenBank:CN217215] & $20: 1.4$ & ENSGALG0000000I903 & $\begin{array}{l}\text { Putative orthologue to microtubule-associated protein I, light } \\
\text { chain } 3 \text { alpha (MAPILC3A) }\end{array}$ & tors & M & $\begin{array}{l}0.34 \\
0.07 \\
0.20\end{array}$ \\
\hline [GenBank:CN222258] & $20: 1.7$ & & NA & tors & $P$ & $\begin{array}{l}0.18 \\
0.22 \\
0.20\end{array}$ \\
\hline [GenBank:CN22069I] & $20: 3.8$ & & NA & tors & FP & $\begin{array}{l}-0.15 \\
-0.19 \\
-0.17\end{array}$ \\
\hline [GenBank:CN22I589] & $20: 5.2$ & ENSGALG00000004|43 & $\begin{array}{l}\text { Putative orthologue to tyrosine 3-monooxygenase/tryptophan 5- } \\
\text { monooxygenase activation protein, beta isoform (YWHAB) }\end{array}$ & tors & MP & $\begin{array}{l}-0.23 \\
-0.06 \\
-0.15\end{array}$ \\
\hline [GenBank:CN22758I] & $20: 5.3$ & ENSGALG00000023846 & NA & tors & $\mathrm{F}$ & $\begin{array}{l}0.01 \\
0.16 \\
0.09\end{array}$ \\
\hline [GenBank:CN236828] & $20: 5.3$ & ENSGALG00000004I70 & Adenosine deaminase (ADA) & tors & FP & $\begin{array}{l}-0.27 \\
-0.69 \\
-0.48\end{array}$ \\
\hline [GenBank:CN235806] & $20: 5.3$ & & NA & tors & M & $\begin{array}{l}-0.26 \\
-0.09 \\
-0.18\end{array}$ \\
\hline [GenBank:CN219753] & $20: 5.5$ & & NA & tors & ALL & $\begin{array}{l}0.21 \\
0.28 \\
0.25\end{array}$ \\
\hline [GenBank:CN232642] & $20: 8.4$ & ENSGALG00000005635 & Transcription factor-like 5 (TCFL5) & tors & $P$ & $\begin{array}{l}-0.12 \\
-0.11 \\
-0.11\end{array}$ \\
\hline
\end{tabular}


Table 3: Differentially expressed transcripts located to QTL-regions for bone traits (Continued)

\begin{tabular}{|c|c|c|c|c|c|c|}
\hline [GenBank:CN227039] & $20: 8.4$ & ENSGALG00000005652 & NA & tors & $\mathrm{P}$ & $\begin{array}{l}-0.12 \\
-0.22 \\
-0.17\end{array}$ \\
\hline [GenBank:CN220570] & $20: 9.0$ & ENSGALG00000005849 & $\begin{array}{l}\text { Putative orthologue to chromosome } 20 \text { open reading frame } 149 \\
\text { (C20orfl49) }\end{array}$ & tors & M & $\begin{array}{l}-0.38 \\
0.01 \\
-0.18\end{array}$ \\
\hline [GenBank:CN218403] & $20: 9.0$ & ENSGALG00000005887 & & tors & MP & $\begin{array}{l}0.52 \\
0.26 \\
0.39\end{array}$ \\
\hline [GenBank:CN223304] & $20: 9.5$ & ENSGALG00000006046 & $\begin{array}{l}\text { Putative orthologue to Dnaj homolog subfamily Cmember } 5 \\
\text { (DNAJC5) }\end{array}$ & tors & MP & $\begin{array}{l}0.37 \\
0.29 \\
0.33\end{array}$ \\
\hline [GenBank:CN23II70] & $20: 9.8$ & & NA & tors & $P$ & $\begin{array}{l}0.15 \\
0.23 \\
0.19\end{array}$ \\
\hline [GenBank:BU/99756] & $20: 10.2$ & ENSGALG00000006657 & $\begin{array}{l}\text { Microtubule-associated protein RP/EB family member I (MAPREI) } \\
*\end{array}$ & tors & MP & $\begin{array}{l}-0.20 \\
-0.13 \\
-0.16\end{array}$ \\
\hline [GenBank:CN228069] & $20: 10.2$ & ENSGALG00000006657 & $\begin{array}{l}\text { Microtubule-associated protein RP/EB family member I (MAPREI) } \\
*\end{array}$ & tors & MP & $\begin{array}{l}-0.35 \\
-0.18 \\
-0.26\end{array}$ \\
\hline [GenBank:CN236/20] & $20: 10.4$ & ENSGALG00000006817 & Putative orthologue to catenin, beta like I (CTNNBLI) & tors & $P$ & $\begin{array}{l}0.08 \\
0.10 \\
0.09\end{array}$ \\
\hline [GenBank:CN232968] & $20: 11.9$ & ENSGALG00000007768 & Putative orthologue to Aurora kinase $A$ (AURKA) & tors & $P$ & $\begin{array}{l}0.34 \\
0.43 \\
0.39\end{array}$ \\
\hline
\end{tabular}

*WIFI and MAPREI are represented by two clones on the microarray \pm [GenBank:CN223165] may represent a retroviral element and may be present also elsewhere in the genome

I Chromosome and positions (in Megabases) of transcripts are based on build 2.1 of the chicken genome

2 Where applicable, Ensembl gene from which transcripts are derived

3 Gene annotation. If applicable, gene name or name of putative orthologue are presented. NA = Not applicable, due to lacking annotation.

4 Previously identified QTLs for traits of femoral bone. ecircl = sex independent QTL for endosteal circumference, nc-bmdl = female specific QTL for noncortical bone mineral density (BMD), bmdl = female specific QTL for various measurements of BMD, torsI = female specific $Q T L$ affecting femoral elasticity in torsion test.

5 The comparison between $W L$ and $R J$ in which transcript was found differentially expressed (FDR-adjusted $p$-value $<0.00 I 5 . M=$ males, $F=$ females, $P=$ population (all $W L$ compared to all $R J$ ), $A L L=M, F$ and $P$.

$6 \mathrm{M}$-values log2(fold change) for M, F and P-comparison, respectively. Negative M-values indicate lower expression in WL.

binding to their receptors in a manner distinct from that of the secreted frizzled related protein receptors (SFRPs) [37]. Interestingly, WIF1 is located in a RJ/WL QTL-region originally identified for body weight and growth [38], which also has pleiotropic effects on many bone traits [11] as well as several other phenotypes $[39,40]$. WL females were found to have stable mRNA levels of WIF1 whereas expression was heterogeneous in RJ-females (Figure 5B). Strong expressional regulation of WIF1 has been observed during BMP2 induced osteoblastic differentiation of murine $\mathrm{C} 2 \mathrm{C} 12$ and MC3T3 cells $[41,42]$. The latter study reported that treatment of C2C12-cells with $\mathrm{LiCl}$ had a stimulatory effect on WIF1 expression, indicating that WIF1 expression is regulated by wnt-signaling components. Furthermore, co-expression of WIF1 and the transcription factor RUNX2 in osteoblastic regions of all bones in the head and the axial skeleton was observed in mice at embryonic day 16.5 [41]. RUNX2 is a master regulator of osteoblastic differentiation, and co-expression between WIF1 and RUNX2 therefore indicates a role of WIF1 in this process. Furthermore, WIF1 has been reported to be expressed in trabecular but not cortical bone of mature mice [42]. This is intriguing because trabecular bone has a much faster turnover as compared to cortical bone, a relationship analogous to the contrast- ing lability between medullary- and cortical bone in chicken. Syndecan 3 (SDC3) has also previously been implicated in bone signaling [43]. It had higher expression in WL and its expression pattern was highly correlated with WIF1 in hierarchical clustering of all probes representing the 779 transcripts identified as differentially expressed between WL and RJ (Additional File 2). We speculate that in reproductive female chicken, expression of WIF1 and SDC3 is induced in medullary bone in response to bone remodeling accompanying egg-laying.

Two probes targeting immunoglobulin-like receptor CHIR-A ([GenBank:CN233569] and [GenBank:CN233552]) indicated lower levels of expression in $\mathrm{WL}$ than in RJ $(\mathrm{M}$-value $=-1)$. The CHIR-A protein shows homology to osteoclast associated receptor (OSCAR), which has been shown to inhibit the formation of osteoclasts from bone-marrow precursor cells stimulated by osteoblasts [44]. Although CHIR-A has yet not been anchored to a chicken chromosome, synteny between human 19q13.4 and chicken micro-chromosome E64 [45] suggests location on this micro-chromosome.

LIM and senescent cell antigen-like domains 1 (LIMS1) and Ran binding protein 2 (RANBP2) are closely located 

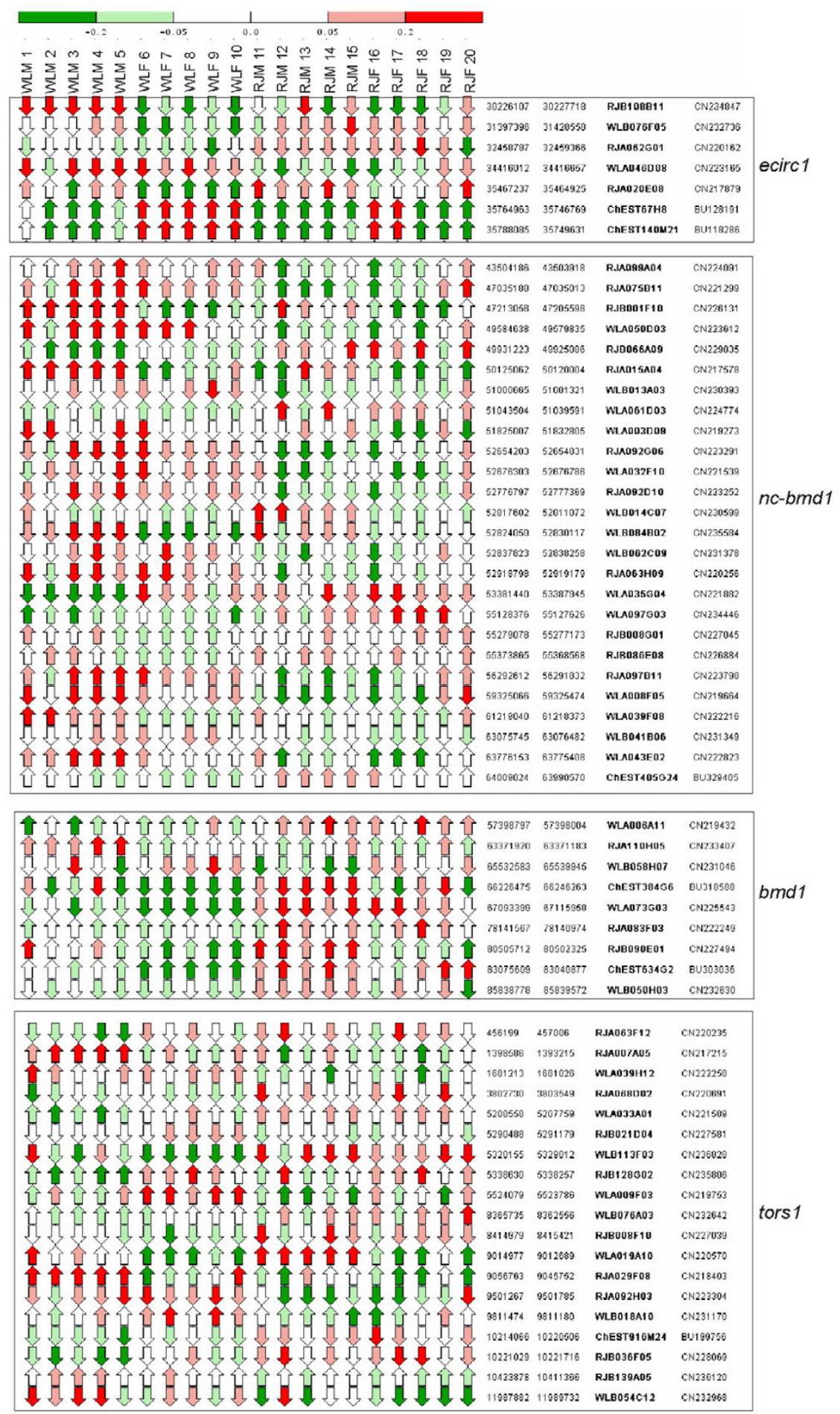

\section{Figure 7}

Relative expression values of differentially expressed transcripts located in QTL-regions. Along each QTL-interval, directions of arrows visualize orientation of expression (i.e. sense or antisense strand). Arrow colors visualize direction and magnitude of log2(sample channel fluorescence/reference channel fluorescence) according to upper scale bar. Red arrows indicate more expression in sample than in reference whereas green arrows indicate more expression in reference. 
Table 4: Overrepresented Gene Ontologies among 604 probes showing differential expression in sex-independent comparison between WL and RJ.

\begin{tabular}{|c|c|c|c|c|c|}
\hline Type 1 & GO-ID 2 & GO-Name & List Hits 3 & Total Hits 4 & EASE-score $^{5}$ \\
\hline C & GO:0005842 & cytosolic large ribosomal subunit (sensu Eukaryota) & 12 & 45 & $6.21 \mathrm{E}-09$ \\
\hline$P$ & GO:00064I2 & protein biosynthesis & 16 & 143 & I.88 E-07 \\
\hline C & GO:0005843 & cytosolic small ribosomal subunit (sensu Eukaryota) & 8 & 32 & $3.53 \mathrm{E}-06$ \\
\hline C & GO:0005840 & ribosome & 9 & 45 & $6.91 \mathrm{E}-06$ \\
\hline$P$ & GO:0007I65 & signal transduction & 24 & 428 & $6.08 \mathrm{E}-05$ \\
\hline $\mathrm{F}$ & GO:0003735 & structural constituent of ribosome & 11 & 97 & 1.79 E-04 \\
\hline$P$ & GO:0000004 & biological_process unknown & 72 & 2067 & $2.28 \mathrm{E}-04$ \\
\hline $\mathrm{F}$ & GO:0003723 & RNA binding & 20 & 268 & $2.41 \mathrm{E}-04$ \\
\hline$P$ & GO:000646I & protein complex assembly & 7 & 62 & $4.98 \mathrm{E}-04$ \\
\hline C & GO:0005856 & cytoskeleton & 11 & 108 & $5.03 \mathrm{E}-04$ \\
\hline$P$ & GO:0006508 & proteolysis and peptidolysis & 10 & $|3|$ & $8.84 \mathrm{E}-04$ \\
\hline C & GO:0005813 & centrosome & 6 & 39 & 1.05 E-03 \\
\hline C & GO:0005794 & Golgi apparatus & 9 & 94 & $2.45 \mathrm{E}-03$ \\
\hline$P$ & GO:0006955 & immune response & 7 & 81 & $2.50 \mathrm{E}-03$ \\
\hline$P$ & GO:0007268 & synaptic transmission & 9 & 128 & $2.78 \mathrm{E}-03$ \\
\hline$P$ & GO:0006629 & lipid metabolism & 6 & 64 & $3.29 \mathrm{E}-03$ \\
\hline $\mathrm{F}$ & GO:0005554 & molecular_function unknown & 62 & $|46|$ & $5.76 \mathrm{E}-03$ \\
\hline $\mathrm{F}$ & GO:0016301 & kinase activity & 6 & 57 & $7.39 \mathrm{E}-03$ \\
\hline $\mathrm{F}$ & GO:0008248 & pre-mRNA splicing factor activity & 6 & 58 & $8.06 \mathrm{E}-03$ \\
\hline $\mathrm{C}$ & GO:0005622 & intracellular & 12 & 178 & $9.61 \mathrm{E}-03$ \\
\hline C & GO:0008372 & cellular_component unknown & 71 & 1763 & 0.013 \\
\hline$P$ & GO:0006468 & protein amino acid phosphorylation & 9 & $|7|$ & 0.017 \\
\hline$P$ & GO:0008283 & cell proliferation & 7 & 134 & 0.035 \\
\hline $\mathrm{C}$ & GO:0005634 & nucleus & 62 & 1587 & 0.035 \\
\hline $\mathrm{F}$ & GO:0003924 & GTPase activity & 6 & 81 & 0.037 \\
\hline C & GO:0016021 & integral to membrane & 47 & 1179 & 0.047 \\
\hline
\end{tabular}

I Top-level Gene Ontology: $\mathrm{P}=$ biological process, $\mathrm{C}=$ cellular component, $\mathrm{F}=$ molecular function

2 Gene Ontology IDs of enriched terms

3 List Hits to Category: Numbers of DE probes on microarray belonging to specific GO-IDs. Total numbers of occurrences of $\mathrm{C}$, $\mathrm{P}$ and $\mathrm{F}$ among $604 \mathrm{DE}$ probes were: $\mathrm{C}=408, \mathrm{P}=403$ and $\mathrm{F}=415$.

4 Total Hits to Category: Total numbers of probes on microarray belonging to specific GO-ID. Total numbers of occurrences of $\mathrm{C}$, $\mathrm{P}$ and $\mathrm{F}$ among all probes on microarray were: $\mathrm{C}=\mid 3074, \mathrm{P}=17435$ and $\mathrm{F}=13433$.

5 EASE-Score: Indicates the statistical significance of the observed overrepresentation.

on chicken chromosome 1 and were both expressed in higher amounts in RJ (Table 2). LIMS1 is a focal adhesion protein which together with integrin linked kinase 1 (ILK1) and alpha-parvin (PARVA) forms a complex which regulates cell shape, motility, and survival [46]. Also associated to focal adhesions, cytoplasmic protein tyrosine kinase (PTK2) and vinculin (VCL) were expressed in higher amounts in RJ (Table 2). PTK2 is activated by binding of ligands such as integrins and growth factors to their receptors and it was recently proposed that interactions between vinculin, talin, and actin filaments constitute a slippage interface between the cytoskeleton and integrins [47]. Large inter-individual differences in expression levels were observed for EGF-like repeats- and discoidin Ilike domains-containing protein 3 (EDIL3). qPCR revealed that all female WL and one female $\mathrm{RJ}$ had at least 95-fold higher expression levels of EDIL3 than the other individuals most of which had no detectable expression (Fig. 3G). The EDIL3 protein adheres to endothelial cells through integrin A5/integrin B3 receptor binding [48,49] and promotes angiogenesis by inducing expression of pro-angiogenic molecules [50]. Possibly, a stable expression of EDIL3, as seen in WL-females is a result of them having a high turnover rate of the vascular medullary bone due to intense selection for egg production. The individual heterogeneity in expression among RJ-females could similarly be explained by their lower rate of egg production, with medullary bone not being subject to constant remodeling.

The observation that several DE transcripts have functional convergence at integrin signaling/focal adhesion is interesting and makes it tempting to speculate that these signaling pathways have become perturbed during domestication or due to selection for egg production in $\mathrm{WL}$, possibly resulting in altered bone metabolism.

\section{Differential expression in QTL-regions}

Of 779 unique DE transcripts, 57 were found to be localized within previously identified QTL-regions for bone traits (Table 3). Three of these QTLs had sex dependent effects in the RJ/WL-intercross population previously 
studied [11]. QTL ecirc1 on chromosome 1 had sex independent effects and the WL-allele conferred larger circumference of the femoral endosteum. At QTL $n c-b m d 1$ also on chromosome 1 , female RJ-allele homozygotes were bestowed with higher noncortical BMD (medullary and/ or trabecular BMD), whereas at QTL bmd1 on chromosome 2 the WL-allele was associated with higher noncortical BMD as well as higher total BMD in females. For tors1 on chromosome 20, female WL-allele bearers have more rigid femurs in rigidity tests by torsion. In Table 3 is indicated for which WL/RJ-contrast DE was observed, as this may aid in interpreting the significance of an overlap between DE and QTL.

Peroxisomal D3, D2-enoyl-CoA isomerase (PECI) which is present in QTL-region $b m d 1$ was expressed in higher levels in RJ (tables 1 and 2). PECI is a peroxisomal enzyme catalyzing an isomerization step required for the beta-oxidation of unsaturated fatty acids, and has not previously been implicated in bone signaling pathways. The genomic location of PECI is very close to the peak of QTL bmd1 [11] and the statistical significance as well as magnitude of differential expression (sex-independent M-value of -0.42) is similar regardless of contrast between WL and RJ. Due to these observations and despite no prior association to bone metabolism, we regard PECI as a QTL-candidate gene. Ribosomal protein L18A (RPL18A) was expressed in higher levels in RJ $(M=-0.27)$ and the gene resides within QTL-region ecirc1. In GO-enrichment analysis, transcripts encoding ribosomal proteins were identified as overrepresented among DE transcripts, making RPL18A a QTL-candidate gene.

The probe targeting [GenBank:CN223165] was expressed in higher levels in WL ( $M=0.40$ and 0.32 in male- and sex independent contrast between $\mathrm{WL}$ and RJ, respectively). In protein BLAST search, [GenBank:CN223165] had highest similarity to a gag/pol polyprotein from avian myeloblastosis virus and was also highly similar to an avian endogenous retroviral insertion localized within the confidence interval of the pleiotropic QTL ecirc1. Interestingly, several isolates of avian myeloblastosis-associated virus (MAV) and avian leukosis virus (ALV) can induce osteopetrosis in chicken and may also affect growth (reviewed in [51]). Osteopetrosis is a bone remodeling disorder characterized by an increase in bone density, and it is therefore tempting to speculate that the retroviral insertion could be causative of the pleiotropic QTL, for which the WL-allele confers higher phenotypic values both for bone and growth traits.

Theoretically, any genetic element which segregates between RJ and WL and which is localized to a QTL-region could be responsible for QTL-effects. Based on gene function as well as magnitude and statistical significance of
$\mathrm{DE}$, the best candidates among herein identified DE-genes include: WIF1, PECI, RPL18A and the retroviral insertion represented by a probe targeting [GenBank:N223165].

\section{GO-term enrichment analysis}

GO-term enrichment-analysis of herein identified DEprobes could lead to identification of transcripts involved in signaling pathways having been perturbed between RJ and WL. It is however important to keep in mind that GOenrichment analysis should be regarded primarily as a rough tool, which could aid in interpretation of data but also that obtained results require manual revision. The list of herein identified differentially expressed transcripts was enriched for certain GO-terms (Table 4). Prominent GO-categories identified in this study (Table 4), were those associated to the ribosome and to protein biosynthesis. Upon examination of probes contributing to overrepresentation of GO-terms; "cytosolic large and small ribosomal subunits", "protein biosynthesis", "ribosome", "structural constituent of ribosome", "RNA-binding" and "intracellular", we observed that 18 probes, representing transcripts encoding 15 ribosomal proteins were largely responsible for enrichment of these GO-terms. Inter-individual differences in expression for probes enriched in GO:0005842 and GO:0005843 are presented as a heat map in Figure 8. Probes for all 15 transcripts had lower expression levels in WL than in RJ, and had a mean Mvalue of -0.31 . BLAST-searches of probe sequences for each ribosomal protein against all chicken cDNAs and against the chicken genome revealed localization to separate loci in the chicken genome and very low intersequence homology among probes, thus excluding the possibility of cross-hybridization as explanation for the observed overrepresentation. Of the eighteen probes enriched in GO:0005842 and GO:0005843, seven were derived from red junglefowl EST-libraries while the remaining eleven were derived from White Leghorn ESTlibraries, suggesting that SNPs in the WL were not causative of differential expression. Interestingly, eukaryotic translation initiation factor 2, subunit 3 (EIF2S3) and Eukaryotic translation initiation factor 4 , gamma 2 (EIF4G2) were also identified as DE in all contrasts between RJ and WL (Table 2) and were, analogously to the ribosomal proteins, expressed in lower levels in WL. When examining transcripts identified as DE in the sex independent contrast we noted that Eukaryotic translation elongation factor 1 alpha 1 (EEF1A1) and Eukaryotic translation elongation factor 2 (EEF2), were both expressed in lower levels in WL $(\mathrm{M}$-values $=-0.25$ and 0.32 , respectively). The observation that transcripts encoding 15 ribosomal proteins as well as several translation initiation and elongation factors had lower levels of expression in $\mathrm{WL}$ is intriguing. We speculate that one route, through which selection acted when desired traits 
were established in the $\mathrm{WL}$, involved the alteration of pathways affecting protein biosynthesis.

Upon examination of transcripts contributing to other overrepresented GO-terms no apparently perturbed pathways were identified, possibly due to the limited coverage of the microarray.

\section{Conclusion}

We have utilized microarray technology to compare global gene expression between the domestic breed White Leghorn (WL) and its wild ancestor, the red junglefowl (RJ). When contrasting gene expression between the two chicken lines we identified differential expression (DE) for 837 microarray probes, representing 779 unique transcripts. Some of the 779 DE transcripts are encoded by genes with functions with interest with regard to bone metabolism (e.g. WDR5, Syndecan 3, WIF1, CHIR-A) and 57 were found to be localized within QTL-regions for bone traits. Among DE genes located to QTL regions for bone traits, WIF1, PECI, RPL18A and a retroviral insertion will be pursued as candidate QTL-genes. Ongoing fine mapping of QTL-regions will decrease confidence intervals of identified QTLs and thus limit the number of DE transcripts localized therein.

In search for enriched Gene Ontology categories among DE transcripts, it was observed that transcripts encoding ribosomal proteins were highly enriched, all having lower expression levels in the WL. Further examination revealed that four transcripts encoding translation initiation and elongation factors were analogously to the ribosomal proteins also expressed in lower levels in $\mathrm{WL}$, possibly suggesting that protein biosynthesis pathways have become perturbed during the selection for desired phenotypes in the WL.

\section{Methods}

\section{Microarray experiments}

\section{Microarrays}

The microarrays used in this study (KTH UniChicken $2 \times 14 \mathrm{k}$ cDNAv1) were developed at the Royal Institute of Technology (RIT) in Stockholm, and comprise 13907 Expressed Sequence Tag (EST)-clones spotted in duplicate. Of the EST-clones, 12742 originated from red junglefowl and White Leghorn brain- and testis libraries manufactured at the Royal Institute of Technology in Stockholm, Sweden [52]. 1136 clones originate from the BBSRC Gallus gallus EST database and these were included because of their biological functions. The remaining 29 clones were created at the Department of Medical Biochemistry and Microbiology at Uppsala University by a representational difference analysis (RDA) approach. Details regarding cDNA amplification, purification and printing are available through the ArrayExpress micro- array data repository using the array accession number AMEXP-266.

\section{Chicken lines, tissue sampling and RNA isolation}

The red junglefowl line originates from Thailand and has been kept at a population size of approximately 30 males and 30 females for four generations. The WL line (Line L13) is kept at the Swedish University of Agriculture (SLU) and has been maintained at a population size of 30 males and 30 females. The L13-line is not a commercial hybrid line, but has been specifically selected for egg-weight since the beginning of the 1970's [53]. All animals were kept in the same facility during their entire lives (further described in [40]). Briefly, the animals were kept in groups of about 35 animals in pens measuring $3 \times 3 \mathrm{~m}$, containing perches, wood-shavings, commercial chicken feed and water, both ad lib. When the birds started to lay eggs, the pens were equipped with group nests on the floor. Room temperature was kept at about 22 degrees Celsius, and light levels at about 30 Lux, with a 12/12 hour light/dark rhythm. Five individuals representing each sex from WL (strain L13) and from red junglefowl were sacrificed at 40 weeks of age. Immediately post mortem femoral bones were thoroughly stripped of soft tissue and were then snap frozen in liquid nitrogen and stored at $-70^{\circ} \mathrm{C}$ until further use. Midshafts of femurs were ground to a fine powder with a mortar while being submerged in liquid nitrogen. RNA was extracted with Trizol (Invitrogen) and the resulting total RNA was purified on RNeasy spin columns (Qiagen, Hilden, Germany) accord-

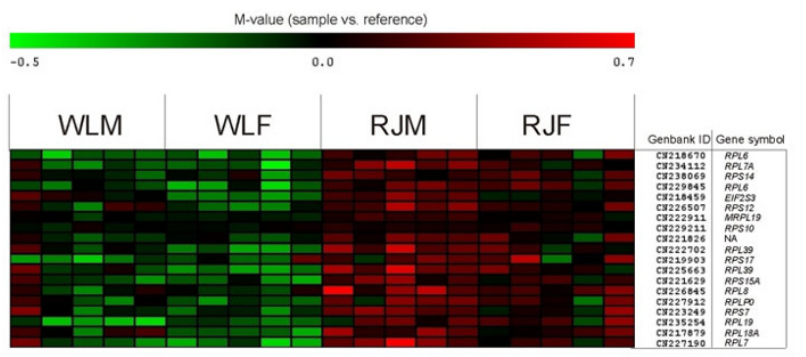

\section{Figure 8}

Heat map illustrating expression ratios ( $\log 2$ (sample fluorescence/reference fluorescence)) for probes from enriched Gene Ontology categories GO:0005842 and GO:0005843, representing cytosolic large and small large ribosomal subunits, respectively. WLM $=$ White Leghorn males, WLF = White Leghorn females, RJM = red junglefowl males, RJF = red junglefowl females. Red colored squares indicate more expression in sample than in reference whereas green indicate more expression in reference. 
ing to the manufacturer's instructions. Twenty $\mu \mathrm{g}$ of individual RNA samples and reference RNA samples (pool consisting of mixed purified RNA from all twenty individuals) were frozen at $-70^{\circ} \mathrm{C}$ until hybridization experiments were initiated. These experiments were approved by the animal research ethics committee in Gothenburg, Sweden (approvals 256/99 and 147-2001).

\section{Assessment of RNA integrity}

All RNA samples were analyzed with the Bioanalyzer (Agilent technologies) and spectrophotometer (Nanodrop). For all samples, the Bioanalyzer data revealed distinct 28S- and 18 S ribosomal RNA bands and 28S/18S ribosomal RNA ratios ranged between 1.2 and 1.5, indicating RNA of quality suitable for expression analysis.

\section{CDNA-synthesis, fluorophore labeling, hybridization and washing} $20 \mu \mathrm{g}$ RNA from each individual and $20 \mu \mathrm{g}$ reference RNA were subjected to cDNA synthesis using reverse transcriptase (Superscript II, Invitrogen) for $2 \mathrm{~h}$ at $42^{\circ} \mathrm{C}$, during which deoxyribonucleic acids and aminoalyl-labeled Uracil were incorporated into cDNA-strands. Remaining RNA was removed from the cDNA sample by $\mathrm{NaOH}$ mediated hydrolysis [54] (protocol SOP 002). Purified aminoalyl-labeled cDNA was purified on silica membrane spin colons (Qiagen, Hilden, Germany), after which one of the fluorophores Cy3 or Cy5 (Amersham biosciences) were attached to the aminoalyl at Uracil residues. Two subsequent silica membrane spin column purification steps were performed to remove unbound fluorophores from cDNA.

In the following step, individual cDNA-samples were hybridized together with the differently labeled reference cDNA on the microarray. Each individual sample was subjected to two hybridizations (dye-swap hybridizations), i.e. the samples were all labeled with $\mathrm{Cy} 3$ in one experiment and with Cy5 in another experiment. The hybridizations were performed in five separate batches; each batch included samples from all groups of individuals i.e. (WLfemales, WL-males, RJ-females and RJ-males) and also included an equal number of Cy3 and Cy5 labeled samples. Protocols for hybridization and washing were developed at KTH and can be found at the website [54] as protocol SOP 003.

\section{Microarray scanning, feature identification and flagging}

Microarrays were subjected to $18 \mathrm{~h}$ of hybridization at $42^{\circ} \mathrm{C}$ while kept in waterproof containers in a water bath, and were subsequently scanned with a G2565BA DNA microarray scanner (Agilent technologies, U.S.A.). Scanning was performed with photo multiplier tube (PMT) settings that gave balanced signals from the two channels. Data-files containing raw fluorescence data (TIFF-files) were imported into the software GenePix (Molecular
Devices Corp., Union City, CA, U.S.A.), in which TIFFfiles generated for Cy3- and Cy5-channels were superimposed upon each other. Spot identification, manual examination of the surface of the array and flagging of spots/ regions with poor quality were all performed in GenePix. Files are available through the ArrayExpress experiment repository (accession number E-TABM-241).

\section{Data analysis}

All microarray analysis steps were conducted with the computer software $\mathrm{R}$ version 2.4.1 [55] with the additional KTH-package [54]

\section{Filtration and normalization of data}

For each array, filtration was performed on spots that had been flagged either manually or by the default settings in the GenePix software. Subsequent filtering was performed for the size of spots, background vs. foreground signal intensity, intensity ratio of fluorescence from the two channels and saturated spots. To normalize signal intensity over the surface of each individual slide and thereafter to normalize signal intensity between all slides, print-tiplowess normalizations were applied [56]. Approximately $70 \%$ of all spots on the arrays were retained after filtration and normalization.

\section{B-test}

Differentially expressed genes were identified using a Bstatistic available in LIMMA [57]. The "B-value" assigned to each gene is the log posterior odds ratio of differential expression versus non-differential expression [58,59]. Correlations between within-array replicate spots were integrated in the statistical model as described in [60]. In total, three contrasts between WL and RJ were performed (male vs. male, female vs. female, and all WL vs. all RJ). In each contrast, individuals belonging to the same group were treated as biological replicates. In the statistical test, probabilities for differential expression ( $\mathrm{p}$-values) were determined for each probe, with these $\mathrm{p}$-values then being adjusted for false discovery rate (FDR) [61]. Probes having obtained FDR-adjusted p-values (q-values) $<0.015$ were considered differentially expressed.

\section{Quantitative PCR}

Individual RNA-samples were subject to DNAse treatment using TURBO-DNAfree (Ambion) and equal amounts of RNA-samples were then reversely transcribed with the High Capacity cDNA reverse transcription kit (Applied Biosystems). Sample cDNA was diluted 20-fold with nuclease-free water and a reference chicken cDNA-sample was diluted 2-, 5-, 10-, 20-, 50-, 100- and 500-fold. Ten $\mu \mathrm{l}$ $2 \times$ TaqMan $^{\circledR}$ Universal PCR Master Mix, No AmpErase ${ }^{\circledast}$ UNG (Applied Biosystems) was mixed with $9 \mu$ l diluted cDNA and $1 \mu$ of Taq-man gene specific assay mix (Applied Biosystems). This mix was subjected to 40 cycles 
of polymerase chain reaction amplification using the ABI Prism 7900 Taqman instrument (Applied Biosystems), where the amount of fluorescence is measured after each cycle. Diluted cDNA-samples from each individual were analyzed in triplicate and each dilution of the reference cDNA was analyzed in duplicate for the purpose of standard curve generation. For all TaqMan assays, correlation coefficients of standard curves exceeded $\mathrm{R}^{2}=0.98$ and standard curve method was subsequently used for relative quantification of target abundance. All assays were designed with the Assays-by-Design software (Applied Biosystems) and featured gene specific primers and exonspanning reporter probes (Table 5). Glyceraldehyde 3phosphate dehydrogenase $(G A P D H)$ was used as reference gene and for each individual the relative expression level of each transcript was normalized relative to GAPDH-expression.

\section{Analysis of differential expression within QTL-regions}

Chromosomal intervals were defined for our four previously identified QTLs for femoral bone traits [11], entitled ecirc1, nc-bmd1, bmd1 and tors1. Confidence intervals (CIs) of QTLs were defined as one unit LOD-drops at both sides of peak LOD-scores. For all QTLs, CIs were delimited by centiMorgan positions located in between microsatellite markers. As a conservative measure, QTL-regions were defined as chromosomal positions confined by microsatellite markers flanking CIs. Chromosomal positions were obtained from the chicken genome draft sequence build $2.1[62]$.

\section{Overrepresentation analysis of Gene Ontology terms}

Clones on the microarray were attributed Gene Ontology (GO) terms by BLAST-analysis of all individual probe sequences against GO peptide sequences obtained from the Gene Ontology project website [63]. BLAST search hits with a similarity cut-off of greater than $E=e^{-10}$ were retained for use in a modified version of the EASE-software [64]. In EASE, GO-term enrichment analysis was performed for probes differentially expressed between all WL and all RJ. In the analysis, each GO-term was assigned an EASE score which is a conservative adjustment of Fisher's exact probability utilizing a jackknife approach. Enriched GO-terms (EASE-score < 0.05) comprising six or more DE probes on the microarray were retained for further analysis.

\section{Clustering of gene expression data}

Clustering was performed in MultiExperiment Viewer $(\mathrm{MeV})$ [65]. Normalized fluorescence intensity values of each dye-swapped experiment were averaged separately for sample and reference channels. Thereafter, for each probe and individual, averaged sample and reference fluorescence values were log2-transformed. Average linkage hierarchical clustering was performed using Euclidian metric. In heat-maps the color of features (probes) were determined by $\log 2$ (sample/reference).

Table 5: Taq-man qPCR-assay details

\begin{tabular}{|c|c|c|c|c|c|}
\hline Gene name & Ensembl transcript ID I & GenBank ID ${ }^{2}$ & Forward primer & Reverse primer & Reporter Probe \\
\hline WDR5 & ENSGALT00000004189 & [GenBank:CN225644] & $\begin{array}{l}\text { CTCTTAAGCTTTGGG } \\
\text { ACTACAGCAA }\end{array}$ & $\begin{array}{l}\text { AGTACTTCTCATTTTT } \\
\text { GTGTCCTGTGT }\end{array}$ & $\begin{array}{l}\text { TCTTCAGGCACT } \\
\text { TTCC }\end{array}$ \\
\hline PTKI & $\begin{array}{l}\text { ENSGALT00000026060 } \\
\text { ENSGALT0000002606 } \\
\text { ENSGALT00000030798 }\end{array}$ & [GenBank:CN232734] & $\begin{array}{l}\text { TCCGCCAGAGGAGT } \\
\text { ACGT }\end{array}$ & $\begin{array}{l}\text { GCGACTCATCCACTG } \\
\text { TTGCTA }\end{array}$ & $\begin{array}{l}\text { CAAGCCAACCTC } \\
\text { CTTTACC }\end{array}$ \\
\hline TGOLN2 & ENSGALT00000023308 & [GenBank:CN22357I] & $\begin{array}{l}\text { CGGCGGCCCAAATC } \\
\text { TG }\end{array}$ & $\begin{array}{l}\text { GCAGCTTTCTTCCAC } \\
\text { TGAATACCT }\end{array}$ & $\begin{array}{l}\text { CCTGGATCAAAA } \\
\text { GATCTAG }\end{array}$ \\
\hline WIFI & ENSGALT00000016042 & [GenBank:BU|28191] & $\begin{array}{l}\text { CGGGATTCGAAGGA } \\
\text { GACCAAT }\end{array}$ & $\begin{array}{l}\text { TCTTACCCATACATTT } \\
\text { TCСТCСАTTTCG }\end{array}$ & $\begin{array}{l}\text { ATGGCATTTACT } \\
\text { GATTTCAC }\end{array}$ \\
\hline GAPDH & $\begin{array}{l}\text { ENSGALT000000 I } 4280 \\
\text { ENSGALT00000023323 }\end{array}$ & [GenBank:CN233267] & $\begin{array}{l}\text { GGAGTCCACTGGTG } \\
\text { TCTTCAC }\end{array}$ & $\begin{array}{l}\text { GCTGAGATGATAACA } \\
\text { CGCTTAGCA }\end{array}$ & $\begin{array}{l}\text { CCCTTCAGATGA } \\
\text { GCCCCAG }\end{array}$ \\
\hline EDIL3 & $\begin{array}{l}\text { ENSGALT00000025199 } \\
\text { ENSGALT00000025200 } \\
\text { ENSGALT00000025201 }\end{array}$ & [GenBank:CN224434] & $\begin{array}{l}\text { CCTACAAGCTTGCC } \\
\text { TACAGTAATGA }\end{array}$ & $\begin{array}{l}\text { ACATTCTTCCGGTGT } \\
\text { GTGTCAT }\end{array}$ & $\begin{array}{l}\text { CCTGGAAAACCT } \\
\text { TGTCCTTC }\end{array}$ \\
\hline CDCA8 & $\begin{array}{l}\text { ENSGALT00000000432 } \\
\text { ENSGALT00000008916 }\end{array}$ & [GenBank:CN226240] & $\begin{array}{l}\text { GTCTTCATTACCGTT } \\
\text { CCTGTTGGA }\end{array}$ & $\begin{array}{l}\text { CCTCCGGATTGAGAT } \\
\text { GAAGAAGATT }\end{array}$ & $\begin{array}{l}\text { CTGTTAAACGAA } \\
\text { TGCTCTCCC }\end{array}$ \\
\hline LIMSI & ENSGALT00000027I30 & [GenBank:CN228750] & $\begin{array}{l}\text { GCAGTTTCCTGAAG } \\
\text { GGCTCTT }\end{array}$ & $\begin{array}{l}\text { ACCACACTGATGGCA } \\
\text { GCAA }\end{array}$ & $\begin{array}{l}\text { TTCСТСССТTCA } \\
\text { ААСТСАТ }\end{array}$ \\
\hline NCE2 & ENSGALT00000006045 & [GenBank:CN227630] & $\begin{array}{l}\text { GCTGGGCTCCAACT } \\
\text { AGAACATT }\end{array}$ & $\begin{array}{l}\text { CAAAGGATCGTCAAA } \\
\text { ATTCAGAAGATCAG }\end{array}$ & $\begin{array}{l}\text { CCCCAGACAACA } \\
\text { TCCTTT }\end{array}$ \\
\hline NDUFA7 & ENSGALT00000000895 & [GenBank:CN225|83] & $\begin{array}{l}\text { CGGCTCCGCAACTT } \\
\text { CCT }\end{array}$ & $\begin{array}{l}\text { GCTGCGTCCTCTTGG } \\
\text { AGATC }\end{array}$ & $\begin{array}{l}\text { CTGGAGGTCCCG } \\
\text { CCCC }\end{array}$ \\
\hline
\end{tabular}

I Transcripts targeted by each Taq-man assay. Specified are Ensembl transcript IDs.

${ }^{2}$ GenBank ID of probe for which assay was designed. 


\section{Phenotyping of the femoral metaphysis}

The femurs, from which RNA had previously been prepared from the midshaft were subjected to phenotyping by peripheral Quantitative Computerized Tomography (pQCT). pQCT was performed with the Stratec pQCT XCT Research SA instrument (Stratec Medizintechnik) operating at a resolution of $70 \mu \mathrm{m}$. Noncortical BMD, which in the female bird reflects BMD of both trabecular and medullary bone was determined ex vivo, with one metaphyseal pQCT scan of the region situated at approximately $5 \%$ of bone length from the distal end of femur, and the noncortical bone was defined by setting an inner threshold to density mode $(600 \mathrm{mg} / \mathrm{cm} 3)$.

\section{Abbreviations \\ cDNA: Complementary DNA}

DE: Differential expression

GO: Gene Ontology

QTL: Quantitative Trait Loci

\section{Authors' contributions}

CJR carried out the molecular genetic studies, performed statistical analyses and drafted the manuscript. JLI conceived software for GO-analysis and performed statistical analyses. CF collected tissue, was involved in array creation (cDNA libraries and RDA clones) and contributed to qPCR- and GO-analysis. PS developed the microarray. JLU contributed to experimental design and provided microarray facility resources. PJ was responsible for breeding and maintenance of chicken lines. AK and LA conceived the study and participated in its design and coordination. All authors contributed to, read and approved the final manuscript.

\section{Additional material}

\section{Additional File 1}

Top tables of differentially expressed probes $(q-v a l u e<0.015)$ identified in contrast All WL vs. All, RJ, and in corresponding sex-specific contrasts. Positive M-values indicate higher expression in WL, whereas negative Mvalues indicated more expression in RJ.

Click here for file

[http://www.biomedcentral.com/content/supplementary/14712164-8-208-S1.xls]

\section{Additional File 2}

Hierarchical clustering of microarray data for 837 probes, corresponding to 779 differentially expressed in three contrasts between WL and RJ. Click here for file

[http://www.biomedcentral.com/content/supplementary/14712164-8-208-S2.jpeg]

\section{Additional File 3}

Along $x$-axis, individuals included in experiment are presented $(1-5=$ WL males, $6-10=W L$ females, $11-15=R J$ males and $16-20=R J$ females) On the $\gamma$-axis, mean $M$-value for sample vs. reference is presented. Mean M-values are based on signal from 124 separate spots on microarray all containing a probe targeting GAPDH (used as an endogenous control in the microarray experiment)

Click here for file

[http://www.biomedcentral.com/content/supplementary/14712164-8-208-S3.jpeg]

\section{Additional File 4}

Metaphyseal images of female femurs from which RNA was derived for the microarray study. Images were derived from phenotyping of the femoral metaphysis by peripheral Quantitative Computerized Tomography $(p Q C T)$. The same femoral bones, from which RNA was prepared from the midshaft, were phenotyped in the distal metaphysis by one $p Q C T$-scan at approximately $5 \%$ of bone length. Arrows indicate appearance of trabecular bone and medullary bone as well as the absence of medullary bone from red junglefowl female number 19. The noncortical bone mineral density (BMD) in $\mathrm{mg} / \mathrm{cm}^{3}$ which in the female metaphysis represents the density of a mix between trabecular and medullary bone is presented below the images corresponding to each individual. The number corresponding to each individual is presented above the images.

Click here for file

[http://www.biomedcentral.com/content/supplementary/14712164-8-208-S4.jpeg]

\section{Additional File 5}

Metaphyseal images of male femurs from which RNA was derived for the microarray study. Images were derived from phenotyping of the femoral metaphysis by peripheral Quantitative Computerized Tomography ( $p Q C T)$. The same femoral bones, from which RNA was prepared from the midshaft, were phenotyped in the distal metaphysis by one $\mathrm{QQCT}$-scan at approximately 5\% of bone length. The number corresponding to each individual is presented above the images.

Click here for file

[http://www.biomedcentral.com/content/supplementary/1471-

2164-8-208-S5.jpeg]

\section{Additional File 6}

Correlation between noncortical BMD of the distal femoral metaphysis and medullary BMD of the femoral midshaft. Results are based on an independent sample consisting of 313 female chicken studied at 200 days of age. Phenotyping was performed by peripheral Quantitative Computerized Tomography and noncortical bone was defined by setting the inner thresholds to $600 \mathrm{mg} / \mathrm{cm}^{3}$ and $1000 \mathrm{mg} / \mathrm{cm}^{3}$ at the distal metaphysis and midshaft, respectively.

Click here for file

[http://www.biomedcentral.com/content/supplementary/14712164-8-208-S6.jpeg] 


\section{Additional File 7 \\ Overrepresented Gene Ontologies (GOs) among 3372 probes showing differential expression ( $q$-values $<0.015)$ in contrast between ten males and ten females (all males compared to all females). Presented are GO- terms which obtained EASE-score $<0.05$ and which comprised six or more DE probes on the microarray. Top-level Gene Ontologies are denoted: $P=$ biological process, $C=$ cellular component, $F=$ molecular function. List Hits to Category indicates numbers of DE probes on microarray belonging to specific GO-IDs. Total numbers of occurrences of C, $P$ and $F$ among 3372 DE probes were: $C=2226, P=2283$ and $F=2224$. Total Hits to Category indicates total numbers of probes on microarray belonging to spe- cific GO-ID. Total numbers of occurrences of $C, P$ and $F$ among all probes on microarray were: $C=13074, P=17435$ and $F=13433$. The EASE- Score indicates the statistical significance of the observed overrepresenta- tion \\ Click here for file \\ [http://www.biomedcentral.com/content/supplementary/1471- 2164-8-208-S7.xls]}

\section{Acknowledgements}

This work was supported by grants from the Wallenberg Consortium North, the Swedish Research Council, Foundation for Strategic Research; the Swedish Research Council for Environment, Agricultural Sciences and Spatial Planning. The Gene Ontology database set-up, query and annotation of the array elements and the integration of TIGR annotations were kindly provided by Zhiliang Hu and James Reecy as part of the NRSP-8 Database coordination effort of the U.S. National Animal Genome Research Program located at lowa State University. We are grateful to Dr. Kenneth Jonsson for providing PQCT-equipment.

\section{References}

I. Kanis JA, Johnell O, Oden A, Sembo I, Redlund-Johnell I, Dawson A, De Laet C, Jonsson B: Long-term risk of osteoporotic fracture in Malmo. Osteoporos Int 2000, I I (8):669-674.

2. Arden NK, Baker J, Hogg C, Baan K, Spector TD: The heritability of bone mineral density, ultrasound of the calcaneus and hip axis length: a study of postmenopausal twins. J Bone Miner Res 1996, II(4):530-534.

3. Harris M, Nguyen TV, Howard GM, Kelly PJ, Eisman JA: Genetic and environmental correlations between bone formation and bone mineral density: a twin study. Bone 1998, 22(2):|4|-I45.

4. Deng HW, Chen WM, Recker S, Stegman MR, Li JL, Davies KM, Zhou Y, Deng $H$, Heaney R, Recker RR: Genetic determination of Colles' fracture and differential bone mass in women with and without Colles' fracture. J Bone Miner Res 2000, I5(7): I243-1252.

5. Burt D, Pourquie $O$ : Genetics. Chicken genome--science nuggets to come soon. Science 2003, 300(5626): 1669.

6. Hillier LW, Miller W, Birney E, Warren W, Hardison RC, Ponting CP, Bork P, Burt DW, Groenen MA, Delany ME, Dodgson JB, Chinwalla AT, Cliften PF, Clifton SW, Delehaunty KD, Fronick C, Fulton RS, Graves TA, Kremitzki C, Layman D, Magrini V, McPherson JD, Miner TL, Minx P, Nash WE, Nhan MN, Nelson JO, Oddy LG, Pohl CS, Randall-Maher J, Smith SM, Wallis JW, Yang SP, Romanov MN, Rondelli CM, Paton B, Smith J, Morrice D, Daniels L, Tempest HG, Robertson L, Masabanda JS, Griffin DK, Vignal A, Fillon V, Jacobbson L, Kerje S, Andersson L, Crooijmans RP, Aerts J, van der Poel JJ, Ellegren H, Caldwell RB, Hubbard SJ, Grafham DV, Kierzek AM, McLaren SR, Overton IM, Arakawa H, Beattie KJ, Bezzubov Y, Boardman PE, Bonfield JK, Croning MD, Davies RM, Francis MD, Humphray SJ, Scott CE, Taylor RG, Tickle C, Brown WR, Rogers J, Buerstedde JM, Wilson SA, Stubbs L, Ovcharenko I, Gordon L, Lucas S, Miller MM, Inoko H, Shiina T, Kaufman J, Salomonsen J, Skjoedt K, Wong GK, Wang J, Liu $B$, Yu J, Yang H, Nefedov M, Koriabine M, Dejong PJ, Goodstadt L, Webber C, Dickens NJ, Letunic I, Suyama M, Torrents D, von Mering C, Zdobnov EM, Makova K, Nekrutenko A, Elnitski L, Eswara P, King DC, Yang S, Tyekucheva S, Radakrishnan A, Harris RS, Chiaromonte
F, Taylor J, He J, Rijnkels M, Griffiths-Jones S, Ureta-Vidal A, Hoffman MM, Severin J, Searle SM, Law AS, Speed D, Waddington D, Cheng Z, Tuzun E, Eichler E, Bao Z, Flicek P, Shteynberg DD, Brent MR, Bye JM, Huckle EJ, Chatterji S, Dewey C, Pachter L, Kouranov A, Mourelatos Z, Hatzigeorgiou AG, Paterson AH, Ivarie R, Brandstrom M, Axelsson E, Backstrom N, Berlin S, Webster MT, Pourquie O, Reymond A, Ucla C, Antonarakis SE, Long M, Emerson J], Betran E, Dupanloup I, Kaessmann $H$, Hinrichs AS, Bejerano G, Furey TS, Harte RA, Raney B, Siepel A, Kent WJ, Haussler D, Eyras E, Castelo R, Abril JF, Castellano S, Camara F, Parra G, Guigo R, Bourque G, Tesler G, Pevzner PA, Smit A, Fulton LA, Mardis ER, Wilson RK: Sequence and comparative analysis of the chicken genome provide unique perspectives on vertebrate evolution. Nature 2004, 432(7018):695-716.

7. Fumihito A, Miyake T, Sumi S, Takada M, Ohno S, Kondo N: One subspecies of the red junglefowl (Gallus gallus gallus) suffices as the matriarchic ancestor of all domestic breeds. Proc Nat Acad Sci U S A 1994, 91 (26): 12505-12509.

8. Dacke CG, Arkle S, Cook DJ, Wormstone IM, Jones S, Zaidi M, Bascal ZA: Medullary bone and avian calcium regulation. Journal of Experimental Biology 1993, 184(I):63-88.

9. Whitehead CC: Overview of bone biology in the egg-laying hen. Poult Sci 2004, 83(2): 193-199.

10. Whitehead CC, Fleming RH: Osteoporosis in cage layers. Poult Sci 2000, 79(7): |033-1041.

II. Rubin CJ, Brandstrom H, Wright D, Kerje S, Gunnarsson U, Schutz K, Fredriksson R, Jensen P, Andersson L, Ohlsson C, Mallmin H, Larsson S, Kindmark A: Quantitative Trait Loci for BMD and Bone Strength in an Intercross Between Domestic and Wildtype Chickens. J Bone Miner Res 2007, 22(3):375-384.

12. Liu YJ, Shen H, Xiao P, Xiong DH, Li LH, Recker RR, Deng HW: Molecular genetic studies of gene identification for osteoporosis: a 2004 update. J Bone Miner Res 2006, 2I(10): I5II-I535.

13. Clop A, Marcq F, Takeda H, Pirottin D, Tordoir X, Bibe B, Bouix J, Caiment F, Elsen JM, Eychenne F, Larzul C, Laville E, Meish F, Milenkovic D, Tobin J, Charlier C, Georges M: A mutation creating a potential illegitimate microRNA target site in the myostatin gene affects muscularity in sheep. Nat Genet 2006, 38(7):8|3-8|8

14. Van Laere AS, Nguyen M, Braunschweig M, Nezer C, Collette C, Moreau L, Archibald AL, Haley CS, Buys N, Tally M, Andersson G, Georges $M$, Andersson L: A regulatory mutation in IGF2 causes a major QTL effect on muscle growth in the pig. Nature 2003 , 425(6960):832-836.

15. Saetre P, Lindberg J, Leonard JA, Olsson K, Pettersson U, Ellegren $\mathrm{H}$, Bergstrom TF, Vila C, Jazin E: From wild wolf to domestic dog: gene expression changes in the brain. Brain Res Mol Brain Res 2004, I 26(2): 198-206

16. Caceres M, Lachuer J, Zapala MA, Redmond JC, Kudo L, Geschwind DH, Lockhart DJ, Preuss TM, Barlow C: Elevated gene expression levels distinguish human from non-human primate brains. Proc Natl Acad Sci U S A 2003, 100(22): I 3030- 3035.

17. Enard W, Khaitovich P, Klose J, Zollner S, Heissig F, Giavalisco P, Nieselt-Struwe K, Muchmore E, Varki A, Ravid R, Doxiadis GM, Bontrop RE, Paabo S: Intra- and interspecific variation in primate gene expression patterns. Science 2002, 296(5566):340-343.

18. Gilad Y, Oshlack A, Smyth GK, Speed TP, White KP: Expression profiling in primates reveals a rapid evolution of human transcription factors. Nature 2006, 440(708I):242-245.

19. Gu J, Gu X: Further statistical analysis for genome-wide expression evolution in primate brain/liver/fibroblast tissues. Hum Genomics 2004, I(4):247-254

20. Khaitovich P, Enard W, Lachmann M, Paabo S: Evolution of primate gene expression. Nat Rev Genet 2006, 7(9):693-702.

21. Khaitovich P, Muetzel B, She X, Lachmann M, Hellmann I, Dietzsch J, Steigele S, Do HH, Weiss G, Enard W, Heissig F, Arendt T, NieseltStruwe K, Eichler EE, Paabo S: Regional patterns of gene expression in human and chimpanzee brains. Genome Res 2004 14(8): | 462-| 473

22. Uddin M, Wildman DE, Liu G, Xu W, Johnson RM, Hof PR, Kapatos G, Grossman LI, Goodman M: Sister grouping of chimpanzees and humans as revealed by genome-wide phylogenetic analysis of brain gene expression profiles. Proc Natl Acad Sci U S A 2004, I 0 I(9):2957-2962.

23. Bronikowski AM, Rhodes JS, Garland T Jr., Prolla TA, Awad TA, Gammie SC: The evolution of gene expression in mouse hippocampus in response to selective breeding for increased 
locomotor activity. Evolution Int J Org Evolution 2004, 58(9):2079-2086.

24. Caetano AR, Johnson RK, Ford JJ, Pomp D: Microarray profiling for differential gene expression in ovaries and ovarian follicles of pigs selected for increased ovulation rate. Genetics 2004, I68(3): 1529-1537.

25. Dierick HA, Greenspan RJ: Molecular analysis of flies selected for aggressive behavior. Nat Genet 2006, 38(9): 1023-I03I.

26. Diez-Tascon C, Keane OM, Wilson T, Zadissa A, Hyndman DL, Baird DB, McEwan JC, Crawford AM: Microarray analysis of selection lines from outbred populations to identify genes involved with nematode parasite resistance in sheep. Physiol Genomics 2005, 2 I (I):59-69.

27. Ka S, Fitzsimmons C, Jacobsson L, Savolainen P, Lundeberg J, Siege $\mathrm{PB}$, Andersson L, Hallbook F: Expression analysis of growth and energy regulation-associated genes in two divergent chicken strains. Ann N Y Acad Sci 2005, 1040:357-359.

28. Yang KT, Lin CY, Liou JS, Fan YH, Chiou SH, Huang CW, Wu CP, Lin EC, Chen CF, Lee YP, Lee WC, Ding ST, Cheng WT, Huang MC: Differentially expressed transcripts in shell glands from low and high egg production strains of chickens using CDNA microarrays. Anim Reprod Sci 2007, I0 I(I-2): I I3-I 24.

29. Andersson L, Georges M: Domestic-animal genomics: deciphering the genetics of complex traits. Nat Rev Genet 2004, 5(3):202-2।

30. Cransberg PH, Parkinson GB, Wilson S, Thorp BH: Sequential studies of skeletal calcium reserves and structural bone volume in a commercial layer flock. Br Poult Sci 200I, 42(2):260-265.

3I. Jensen P, Keeling L, Schutz K, Andersson L, Mormede P, Brandstrom H, Forkman B, Kerje S, Fredriksson R, Ohlsson C, Larsson S, Mallmin $\mathrm{H}$, Kindmark $\mathrm{A}$ : Feather pecking in chickens is genetically related to behavioural and developmental traits. Physiol Behav 2005, 86(I-2):52-60.

32. Hori T, Asakawa S, Itoh Y, Shimizu N, Mizuno S: Wpkci, encoding an altered form of $\mathrm{PKCl}$, is conserved widely on the avian $W$ chromosome and expressed in early female embryos: implication of its role in female sex determination. Mol Biol Cell 2000, II ( I 0):3645-3660.

33. Itoh Y, Melamed E, Yang X, Kampf K, Wang S, Yehya N, Van Nas A, Replogle K, Band MR, Clayton DF, Schadt EE, Lusis AJ, Arnold AP: Dosage compensation is less effective in birds than in mammals. J Biol 2007, 6(I):2

34. Gori F, Divieti P, Demay MB: Cloning and characterization of a novel WD-40 repeat protein that dramatically accelerates osteoblastic differentiation. J Biol Chem 200I, 276(49):465। 5-46522.

35. Gori F, Demay MB: BIG-3, a novel WD-40 repeat protein, is expressed in the developing growth plate and accelerates chondrocyte differentiation in vitro. Endocrinology 2004 I 45(3): 1050- 1054.

36. Krishnan V, Bryant HU, Macdougald OA: Regulation of bone mass by Wnt signaling. I Clin Invest 2006, I | 6(5): 1202-I 209.

37. Hsieh JC, Kodjabachian L, Rebbert ML, Rattner A, Smallwood PM, Samos CH, Nusse R, Dawid IB, Nathans J: A new secreted protein that binds to Wnt proteins and inhibits their activities. Nature 1999, 398(6726):431-436

38. Kerje S, Carlborg O, Jacobsson L, Schutz K, Hartmann C, Jensen $P$, Andersson L: The twofold difference in adult size between the red junglefowl and White Leghorn chickens is largely explained by a limited number of QTLs. Anim Genet 2003 , 34(4):264-274.

39. Wright D, Kerje S, Lundstrom K, Babol J, Schutz K, Jensen P, Andersson L: Quantitative trait loci analysis of egg and meat production traits in a red junglefowlxWhite Leghorn cross. Anim Genet 2006, 37(6):529-534.

40. Schutz KE, Kerje S, Jacobsson L, Forkman B, Carlborg O, Andersson $L$, Jensen $P$ : Major growth QTLs in fowl are related to fearful behavior: possible genetic links between fear responses and production traits in a red junglefowl $x$ white leghorn intercross. Behav Genet 2004, 34(I): 12 I- 130.

4I. Vaes BL, Dechering KJ, Feijen A, Hendriks JM, Lefevre C, Mummery CL, Olijve W, van Zoelen EJ, Steegenga WT: Comprehensive microarray analysis of bone morphogenetic protein 2induced osteoblast differentiation resulting in the identifica- tion of novel markers for bone development. J Bone Miner Res 2002, I 7( I 2):2106-2II8

42. Vaes BL, Dechering KJ, van Someren EP, Hendriks JM, van de Ven CJ, Feijen A, Mummery CL, Reinders MJ, Olijve W, van Zoelen EJ, Steegenga WT: Microarray analysis reveals expression regulation of Wnt antagonists in differentiating osteoblasts. Bone 2005, 36(5):803-8II.

43. Koyama E, Shimazu A, Leatherman JL, Golden EB, Nah HD, Pacifici M: Expression of syndecan-3 and tenascin-C: possible involvement in periosteum development. J Orthop Res 1996, I4(3):403-4I2.

44. Kim N, Takami M, Rho J, Josien R, Choi Y: A novel member of the leukocyte receptor complex regulates osteoclast differentiation. J Exp Med 2002, 195(2):20I-209.

45. Smith J, Paton IR, Murray F, Crooijmans RP, Groenen MA, Burt DW: Comparative mapping of human Chromosome 19 with the chicken shows conserved synteny and gives an insight into chromosomal evolution. Mamm Genome 2002, I3(6):3 I0-3I 5.

46. Fukuda T, Chen K, Shi X, Wu C: PINCH-I is an obligate partner of integrin-linked kinase (ILK) functioning in cell shape modulation, motility, and survival. J Biol Chem 2003, 278(5I):5I324-5I333.

47. Hu K, Ji L, Applegate KT, Danuser G, Waterman-Storer CM: Differential transmission of actin motion within focal adhesions. Science 2007, 3 I 5(5808): III-II5.

48. Hidai C, Zupancic T, Penta K, Mikhail A, Kawana M, Quertermous EE, Aoka Y, Fukagawa M, Matsui Y, Platika D, Auerbach R, Hogan BL, Snodgrass R, Quertermous T: Cloning and characterization of developmental endothelial locus-I: an embryonic endothelial cell protein that binds the alphavbeta 3 integrin receptor. Genes Dev 1998, I 2(I):21-33.

49. Penta K, Varner JA, Liaw L, Hidai C, Schatzman R, Quertermous T: Dell induces integrin signaling and angiogenesis by ligation of alphaVbeta3. I Biol Chem 1999, 274(16): I I I0I-I I I09.

50. Zhong J, Eliceiri B, Stupack D, Penta K, Sakamoto G, Quertermous T, Coleman M, Boudreau N, Varner JA: Neovascularization of ischemic tissues by gene delivery of the extracellular matrix protein Del-I. J Clin Invest 2003, I I 2(1):30-4I.

51. Coffin JM, Hughes SH, Varmus HE: Retroviruses. Edited by: Schaefer S. Cold Spring Harbor Laboratory Press; 1997.

52. Savolainen P, Fitzsimmons C, Arvestad L, Andersson L, Lundeberg J: ESTs from brain and testis of White Leghorn and red junglefowl: annotation, bioinformatic classification of unknown transcripts and analysis of expression levels. Cytogenet Genome Res 2005, I I I (I):79-87.

53. Liljedahl LE, Kolstad N, Sorensen P, Maijala K: Scandinavian selection and cross-breeding experiment with laying hens. I. Background and general outline. Acta Agriculturae Scandinavica 1979, 29:273-285.

54. The KTH-Package for Microarray Data Analysis [http:// www.ktharray.se/]

55. The R Project for Statistical Computing [http://www.rproject.org/]

56. Smyth GK, Speed T: Normalization of cDNA microarray data. Methods 2003, 3 I (4):265-273.

57. Smyth GK: Limma: linear models for microarray data, in Bioinformatics and Computational Biology Solutions using $\mathbf{R}$ and Bioconductor. In Statistics for Biology and Health Edited by: Gentleman R, Carey V, Dudoit S, Irizarry R, Huber W. New York, Springer; 2005.

58. Lonnstedt I, Speed TP: Replicated microarray data. Stat Sin 2002 , I 2:3|-46.

59. Smyth GK: Linear models and empirical bayes methods for assessing differential expression in microarray experiments. Stat Appl Genet Mol Biol 2004, 3( I):Article3.

60. Smyth GK, Michaud J, Scott HS: Use of within-array replicate spots for assessing differential expression in microarray experiments. Bioinformatics 2005, 2 I (9):2067-2075.

61. Benjamini $Y$, Hochberg $Y$ : Controlling the false discovery rate: a practical and powerful approach to multiple testing. Journal of the Royal Statistical Society, Series B Methodological 1995, 57:289-300.

62. Washington University School of Medicine Genome Sequencing Center [http://genome.wustl.edu/]

63. The Gene Ontology project [http://www.geneontology.org/] 
64. Hosack DA, Dennis G Jr., Sherman BT, Lane HC, Lempicki RA: Identifying biological themes within lists of genes with EASE. Genome Biol 2003, 4(I 0):R70.

65. Saeed Al, Sharov V, White J, Li J, Liang W, Bhagabati N, Braisted J, Klapa M, Currier T, Thiagarajan M, Sturn A, Snuffin M, Rezantsev A, Popov D, Ryltsov A, Kostukovich E, Borisovsky I, Liu Z, Vinsavich A, Trush V, Quackenbush J: TM4: a free, open-source system for microarray data management and analysis. Biotechniques 2003, 34(2):374-378.

Publish with Bio Med Central and every scientist can read your work free of charge

"BioMed Central will be the most significant development for disseminating the results of biomedical research in our lifetime. " Sir Paul Nurse, Cancer Research UK

Your research papers will be:

- available free of charge to the entire biomedical community

- peer reviewed and published immediately upon acceptance

- cited in PubMed and archived on PubMed Central

- yours - you keep the copyright
BiolMedcentral 